\title{
Measuring the state and temporal evolution of glaciers in Alaska and Yukon using synthetic-aperture-radar-derived (SAR-derived) 3D time series of glacier surface flow
}

\author{
Sergey Samsonov ${ }^{1}$, Kristy Tiampo ${ }^{2}$, and Ryan Cassotto ${ }^{2}$ \\ ${ }^{1}$ Canada Centre for Mapping and Earth Observation, Natural Resources Canada, 560 Rochester Street, \\ Ottawa, ON K1S5K2 Canada \\ ${ }^{2}$ Earth Science and Observation Center, Cooperative Institute for Research in Environmental Sciences, \\ University of Colorado, Boulder, CO 80309 USA
}

Correspondence: Sergey Samsonov (sergey.samsonov@nrcan-rncan.gc.ca)

Received: 4 September 2020 - Discussion started: 27 October 2020

Revised: 27 July 2021 - Accepted: 29 July 2021 - Published: 6 September 2021

\begin{abstract}
Climate change has reduced global ice mass over the last 2 decades as enhanced warming has accelerated surface melt and runoff rates. Glaciers have undergone dynamic processes in response to a warming climate that impacts the surface geometry and mass distribution of glacial ice. Until recently no single technique could consistently measure the evolution of surface flow for an entire glaciated region in three dimensions with high temporal and spatial resolution. We have improved upon earlier methods by developing a technique for mapping, in unprecedented detail, the temporal evolution of glaciers. Our software computes north, east, and vertical flow velocity and/or displacement time series from the synthetic aperture radar (SAR) ascending and descending range and azimuth speckle offsets. The software can handle large volumes of satellite data and is designed to work on high-performance computers (HPCs) as well as workstations by utilizing multiple parallelization methods. We then compute flow velocity-displacement time series for glaciers in southeastern Alaska during 2016-2021 and observe seasonal and interannual variations in flow velocities at Seward and Malaspina glaciers as well as culminating phases of surging at Klutlan, Walsh, and Kluane glaciers. On a broader scale, this technique can be used for reconstructing the response of worldwide glaciers to the warming climate using archived SAR data and for near-real-time monitoring of these glaciers using rapid revisit SAR data from satellites, such as Sentinel1 (6 or $12 \mathrm{~d}$ revisit period) and the forthcoming NISAR mission (12 d revisit period).
\end{abstract}

\section{Introduction}

The magnitude and direction of glacier flow adjust in response to the warming climate, leading to changes in seasonal flooding and droughts, landscapes and habitats, and ultimately sea level variations. Surface flow is a key variable for determining glacier mass balance (Shepherd et al., 2020), ice thickness (Morlighem et al., 2011; Werder et al., 2019), and surface mass balance (Bisset et al., 2020). Here we present a technique that can be used for measuring the temporal evolution of surface flow for an entire glaciated region in three dimensions (3D) with high temporal and spatial resolution.

Modern techniques and platforms used for monitoring glacier flow include synthetic aperture radar (SAR) (Goldstein et al., 1993; Mohr et al., 1998; Rignot, 2002; Joughin, 2002), the Global Navigation Satellite System (GNSS) (van de Wal et al., 2008; Bartholomew et al., 2010), optical imagery (Berthier et al., 2005; Herman et al., 2011; Dehecq et al., 2015; Fahnestock et al., 2016), and uncrewed aerial vehicles (Immerzeel et al., 2014). Among these, SAR is the only active side-looking sensor with global coverage at high temporal and spatial resolution that can operate in any weather conditions, day or night. SAR techniques comprise displacement measurements with sub-meter to meter-scale precision using speckle offset tracking (SPO) (Strozzi et al., 2002), split-beam interferometry (or multi-aperture interferometry, MAI) (Bechor and Zebker, 2006; Gourmelen et al., 2011), and centimeter-scale differential interferometry (DIn- 
SAR) (Massonnet and Feigl, 1995; Rosen et al., 2000). SPO applies image correlation algorithms to radar data to measure displacements in the satellite range and azimuth directions using two SAR images. Since its early inception, SAR has been used in glacier monitoring for estimating flow velocities, surface flux, tidal variations, grounding line behavior, and subglacial lake activity (Goldstein et al., 1993; Joughin et al., 1995, 1998; Rignot, 1998; Shepherd et al., 2001; Gray et al., 2005; Palmer et al., 2010; Minchew et al., 2017). In this study, we use the SPO technique to produce deformation maps in range and azimuth coordinates that do not require phase unwrapping.

The SAR-derived displacements for a single epoch can be transformed into 3D (north, east, vertical) displacements by either combining multiple datasets or assuming various model constraints (Mohr et al., 1998; Wright et al., 2004; Gourmelen et al., 2007; Kumar et al., 2011; Hu et al., 2014). However, the 3D displacement time series cannot be easily computed due to limitations inherent in the data acquisition strategy. Specifically, SAR data on ascending and descending orbits are usually acquired on different days, often with different incidence angles and varying temporal and spatial resolutions and wavelengths. The multidimensional small baseline subset (MSBAS) methodology (Samsonov and d'Oreye, 2012, 2017; Samsonov, 2019; Samsonov et al., 2020) has been developed specifically for computing multidimensional displacement time series from SAR data acquired with different acquisition parameters.

Historically, three components of mean glacier velocity were computed from DInSAR and/or range offsets by introducing a surface-parallel flow (SPF) constraint. This approach was used for 3D mapping of Greenlandic (Joughin et al., 1998; Mohr et al., 1998) and Himalayan (Kumar et al., 2011) glaciers and validated by independent GNSS (Kumar et al., 2011) measurements. In our previous work (Samsonov, 2019), we adopted the SPF method for computing the 3D flow displacement time series of the Barnes Ice Cap using ascending and descending DInSAR data combined using the MSBAS technique. However, the SPF constraint ignores submergence and emergence velocities and other vertical motion. In some studies, ascending and descending DInSAR (Gray, 2011) or range and azimuth offsets (Wang et al., 2019) were used to compute 3D glacier velocities for a few isolated epochs. Recently, Guo et al. (2020) developed a technique based on MSBAS that computes 3D flow velocity time series from ascending and descending range and azimuth offsets and used it to study Hispar Glacier in central Karakoram. Here, we present our independently developed version of this algorithm, which offers several distinct advantages over Guo et al. (2020). First, our technique does not use weights determined by the pixel spacing. Second, our opensource software provides additional functionalities, such as zeroth-, first- (implemented in Guo et al., 2020), and secondorder Tikhonov regularizations. Third, the user can choose to compute 1D, 2D, constrained 3D, unconstrained 3D (pre- sented in this paper), and 4D (Samsonov et al., 2021a) velocity and/or displacement time series. Finally, the software is also parallelized (OpenMP, MPI), making it suitable for running on high-performance computers (HPCs) or personal workstations.

In contrast to MSBAS-based techniques, Minchew et al. (2017) and Milillo et al. (2017) took a different approach and inferred time-dependent 3D flow velocity by assuming a form for the temporal basis functions based on prior knowledge of the study area. The need for prior knowledge means that this method is not general, so its application is limited to areas where the assumed basis functions should be valid. The advantage of the Minchew et al. (2017) approach is interpretability of the results, a straightforward connection of the results to the physics of the systems being observed, and robust quantification of uncertainties. A recent improvement to Minchew et al. (2017) is Riel et al. (2021), who adopted some of the methods of Riel et al. $(2014,2018)$ and applied them to remote sensing observations of glaciers. From a methodological perspective, this generalizes the approach of Minchew et al. (2017) and allows for a generic set of temporal basis functions, from which a sparsity-inducing optimization is used to identify the simplest set of basis functions that describe the data. The advantage there is also in the interpretability of the results and robust uncertainty quantification, which provides the ability to decompose the observed signal into short- and long-term variations and features the ability to constrain transients, secular, and periodic signals. However, this method still requires a priori knowledge to provide confidence in the resulting basis functions. The technique we present here is complementary because it does not rely on basis functions and provides flexibility at the expense of interpretability of the results, whereas the Minchew et al. (2017) and Riel et al. (2021) techniques sacrifice flexibility in the method for enhanced interpretability of the results.

Here we focus on dynamic changes along six landterminating glaciers in southeastern Alaska during 20 October 2016-21 January 2021: Agassiz, Seward, Malaspina, Klutlan, Kluane, and Walsh glaciers. This technique can be used to analyze 3D flow velocities of glacier surfaces over large regional scales using nearly 3 decades of archived SAR data and for near-real-time monitoring of these glaciers using rapid revisit SAR data.

\section{Model}

The inversion technique described below utilizes ascending and descending range and azimuth speckle offset products computed from SAR data using a speckle offset tracking algorithm implemented in GAMMA software (Wegmuller and Werner, 1997). We chose to use the speckle offsets because their computation does not require phase unwrapping, which is not possible due to large flow velocities in our study area. 


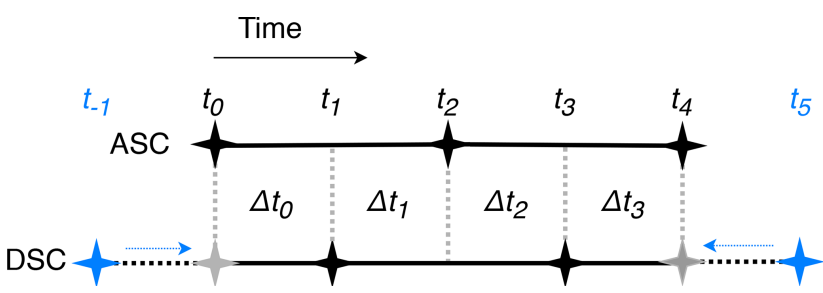

Figure 1. Schematics of the simplified case described by Eq. (3). Ascending and descending SAR acquisitions at time $t_{i}$ are marked with black stars. Horizontal solid lines represent range and azimuth offset maps. Vertical dashed lines divide temporal scale in time intervals $\Delta t_{i}=t_{i+1}-t_{i}$ between consecutive acquisitions. The times of first and last descending acquisitions (marked with blue stars) are adjusted to match the first and last time of ascending acquisitions (marked with gray stars).

The 3D displacement time series are computed by inverting a set of linear equations, first solving for the north, east, and vertical flow velocities $V_{\mathrm{n}, \mathrm{e}, \mathrm{v}}$ for each acquisition epoch (Fialko et al., 2001; Bechor and Zebker, 2006) and then for cumulative 3D flow displacements $D_{\mathrm{n}, \mathrm{e}, \mathrm{v}}$.

$$
\begin{aligned}
& \left(\begin{array}{c}
A \\
\lambda L
\end{array}\right)\left(\begin{array}{c}
V_{\mathrm{n}} \\
V_{\mathrm{e}} \\
V_{\mathrm{v}}
\end{array}\right)=\left(\begin{array}{c}
\mathrm{RO}^{\mathrm{asc}} \\
\mathrm{AO}^{\mathrm{asc}} \\
\mathrm{RO}^{\mathrm{dsc}} \\
\mathrm{AO}^{\mathrm{dsc}} \\
0
\end{array}\right) \\
& D_{\mathrm{n}, \mathrm{e}, \mathrm{v}}^{i+1}=D_{\mathrm{n}, \mathrm{e}, \mathrm{v}}^{i}+V_{\mathrm{n}, \mathrm{e}, \mathrm{v}}^{i} \Delta t_{i}
\end{aligned}
$$

Equation (1a) has a straightforward application: time interval multiplied by velocity is equal to displacement. Here, in matrix form, $\mathrm{RO}$ represents the range and $\mathrm{AO}$ represents the azimuth offsets computed from SAR data; $L$ is the Tikhonov regularization matrix multiplied by the scalar regularization parameter, $\lambda$, and $A$ is the transform matrix constructed from the time intervals between consecutive SAR acquisitions and the range $\left(s_{\rho}\right)$ and azimuth $\left(s_{\alpha}\right)$ directional cosines with north, east, and vertical components:

$$
s_{\rho}=\left\{s_{\mathrm{n} \rho}, s_{\mathrm{e} \rho}, s_{\mathrm{v} \rho}\right\}=\{\sin (\phi) \sin (\theta),-\cos (\phi) \sin (\theta), \cos (\theta)\}
$$$$
s_{\alpha}=\left\{s_{\mathrm{n} \alpha}, s_{\mathrm{e} \alpha}, s_{\mathrm{v} \alpha}\right\}=\{\cos (\phi), \sin (\phi), 0\},
$$

where $\phi$ is the azimuth and $\theta$ is the incidence angle. The azimuth is the satellite heading, measured from the north; it discerns ascending vs. descending orbits. The incidence angle is the angle between the nadir and the look direction from the satellite; it is one of the acquisition parameters of the side-looking SAR sensor.

The need for regularization arises because SAR images from different tracks are acquired at different times, which results in more unknowns than equations, producing a rankdeficient, underdetermined problem. When solving a set of linear equations in general there can be three possible scenarios: the number of equations can be less than, equal to, or greater than the number of unknowns. In the equal case, the matrix is square and no regularization is required (but can still be applied). In the greater case, the least square solution is found using singular value decomposition (SVD); this scenario is common in 1D MSBAS, wherein usually there are more interferograms than single-look complex (SLC) images. In the lesser case, as always in 2D and 3D MSBAS, the solution is found using either the truncated SVD or the zeroth-order Tikhonov regularization. The higher-order regularizations must be applied if the objective is to fill the temporal gaps due to missing data, which results in smoothing and the interpolation of missing values in the temporal domain. We observe that the first- and second-order regularizations work equally well in this case, probably because of slowly changing velocities.

In the $M \times N$ transform matrix $A$ with $M$ rows and $N$ columns, $N$ is equal to the number of available distinct SLC images (with the boundary correction - defined below) minus 1 then multiplied by 3 (i.e., $N=3\left(\sum_{k=1}^{K} N_{\text {slc }}^{k}-1\right)$, where $K$ is the total number of ascending and descending sets and $N_{\text {slc }}^{k}$ is the number of SLC images in $k$ set). $M$ is equal to the total number of range and azimuth offset maps computed from those SLC images (i.e., $M=\sum_{k=1}^{K}\left(N_{\alpha}^{k}+N_{\rho}^{k}\right)$, where $K$ is the total number of ascending and descending sets, $N_{\alpha}^{k}$ is the number of computed azimuth offset maps, and $N_{\rho}^{k}$ is the number of computed range offset maps in $k$ set).

The regularization matrix $L$ has the same number of columns $N$ as the transform matrix $A$, but its number of rows depends on the regularization order. It is equal to $N$ for the zeroth order, $N-3$ for the first order, and $N-6$ for the second order.

The structure of $A$ can be deduced from a simplified example shown in Fig. 1 and described below. In this example, it is assumed that the ascending set consists of three SAR images acquired on $t_{0}, t_{2}$, and $t_{4}$, and the descending set consists of four SAR images acquired on $t_{-1}, t_{1}$, $t_{3}$, and $t_{5}$. Two ascending range $\mathrm{RO}^{\text {asc }}=\left\{\rho_{0-2}^{\text {asc }}, \rho_{2-4}^{\text {asc }}\right\}$ and azimuth $\mathrm{AO}^{\text {asc }}=\left\{\alpha_{0-2}^{\text {asc }}, \alpha_{2-4}^{\text {asc }}\right\}$ offset products are computed from three ascending SAR images, and three descending range $\mathrm{RO}^{\mathrm{dsc}}=\left\{\rho_{-1-1}^{\mathrm{dsc}}, \rho_{1-3}^{\mathrm{dsc}}, \rho_{3-5}^{\mathrm{dsc}}\right\}$ and azimuth $\mathrm{AO}^{\mathrm{dsc}}=$ $\left\{\alpha_{-1-1}^{\mathrm{dsc}}, \alpha_{1-3}^{\mathrm{dsc}}, \alpha_{3-5}^{\mathrm{dsc}}\right\}$ offset products are computed from four descending SAR images (therefore, $M=2+2+3+3=10$ ). A boundary correction (shown as blue arrows in Fig. 1) is applied to the first and last descending offset products $\rho_{-1-1}^{\mathrm{dsc}}$, $\alpha_{-1-1}^{\mathrm{dsc}}, \rho_{3-5}^{\mathrm{dsc}}$, and $\alpha_{3-5}^{\mathrm{dsc}}$ by multiplying by $\left(t_{1}-t_{0}\right) /\left(t_{1}-t_{-1}\right)$ and $\left(t_{4}-t_{3}\right) /\left(t_{5}-t_{3}\right)$ in order to adjust the temporal coverage to match the ascending offset products. The boundarycorrected descending offsets therefore become $\rho_{0-1}^{\mathrm{dsc}}, \alpha_{0-1}^{\mathrm{dsc}}$, $\rho_{3-4}^{\mathrm{dsc}}$, and $\alpha_{3-4}^{\mathrm{dsc}}$. Note that the boundary correction reduces the number of SLC images by two; after correction, $t_{-1}$ effectively becomes $t_{0}$, and $t_{5}$ effectively becomes $t_{4}$ (i.e., reducing the total number of SLC images to five and thus $N=3(5-1)=12)$. The first-order regularization matrix $L$ in this case has 12 columns and 9 rows. 

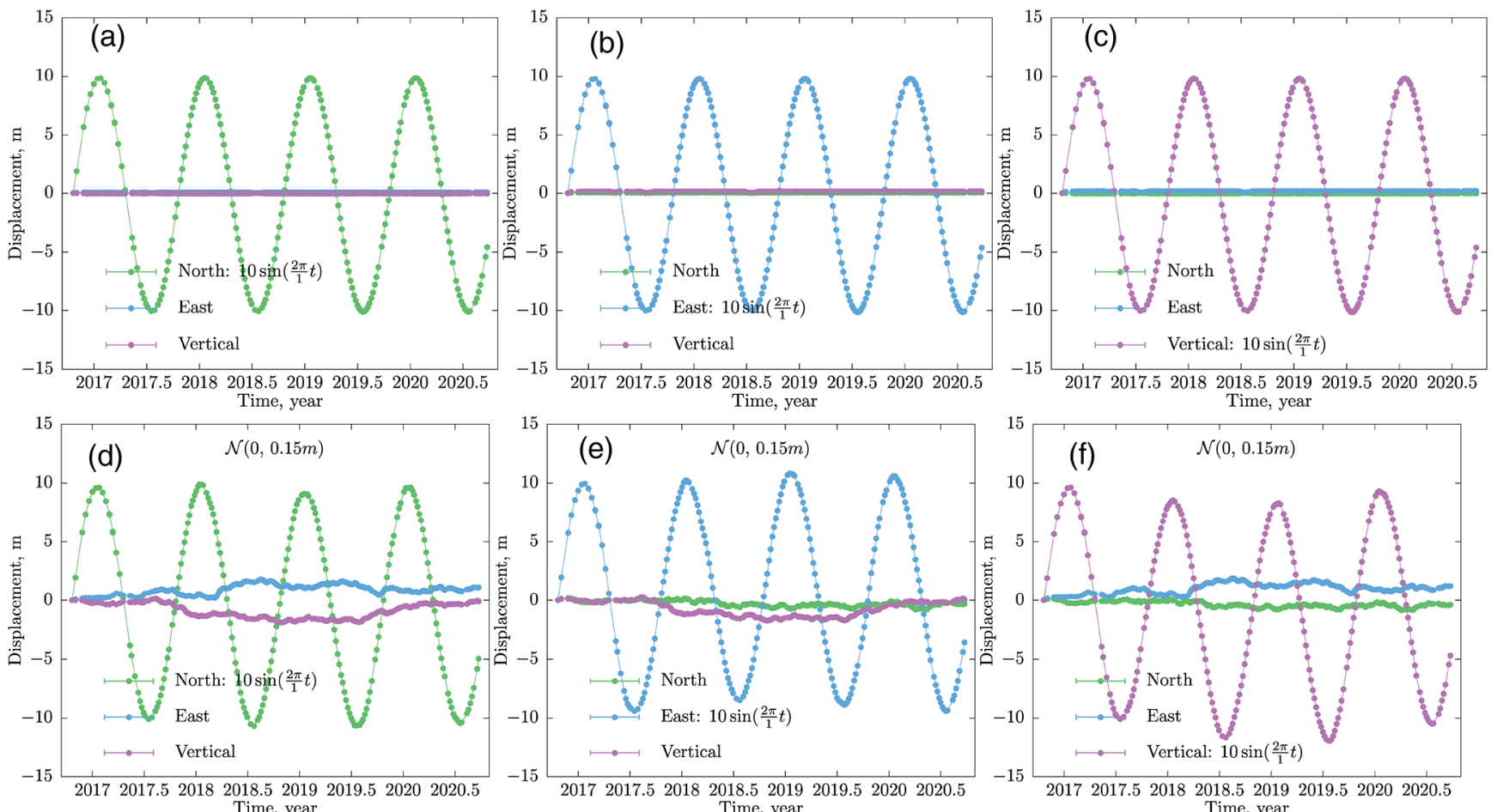

Figure 2. Results of numerical simulations demonstrating the ability of this technique to reconstruct input signal in one of components. Equations of input signals are shown in corresponding subfigure legends; $t$ is time. Harmonic input signals are assumed. Gaussian noise with a mean value of zero and standard deviations of $0.15 \mathrm{~m}$ (which is approximately $10 \%$ of the signal) is added to subfigures in the second row.

Assuming that $\Delta t_{i}=t_{i+1}-t_{i}$ in this simplified example,

Eq. (1a) becomes

\begin{tabular}{|c|c|c|c|c|c|c|c|c|c|c|c|c|c|}
\hline$\left(s_{\mathrm{n} \rho}^{\mathrm{asc}} \Delta t_{0}\right.$ & $s_{\mathrm{e} \rho}^{\mathrm{acc}} \Delta t_{0}$ & $s_{\mathrm{v} \rho}^{\mathrm{acs}} \Delta t_{0}$ & $s_{\mathrm{n} \rho}^{\mathrm{acs}} \Delta t_{1}$ & $s_{\mathrm{a} \rho}^{\mathrm{acs}} \Delta t_{1}$ & $s_{\mathrm{v} \rho}^{\mathrm{acc}} \Delta t_{1}$ & 0 & 0 & 0 & 0 & 0 & 0 & & $\left(\begin{array}{l}\rho_{0}^{\mathrm{asc}} \\
\mathrm{casc}^{2}\end{array}\right.$ \\
\hline $\begin{array}{l}0 \\
\text { asce }\end{array}$ & $\begin{array}{l}0 \\
\text { asc }\end{array}$ & 0 & $\begin{array}{l}0 \\
\text { asc }\end{array}$ & 0 & 0 & $s_{\mathrm{n} \rho}^{\mathrm{asc}} \Delta t_{2}$ & $s_{\mathrm{e} \rho}^{\mathrm{asc}} \Delta t_{2}$ & $s_{v \rho}^{\mathrm{asc}} \Delta t_{2}$ & $s_{\mathrm{n} \rho}^{\mathrm{asc}} \Delta t_{3}$ & $s_{\mathrm{e} \rho}^{\mathrm{asc}} \Delta t_{3}$ & $s_{v \rho}^{\mathrm{asc}} \Delta t_{3}$ & & 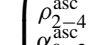 \\
\hline$s_{\mathrm{nd} \alpha}^{\operatorname{sic}} \Delta t_{0}$ & $s_{\mathrm{ex}}^{\mathrm{ase}} \Delta t_{0}$ & $\begin{array}{l}0 \\
0\end{array}$ & $S_{\mathrm{n} \alpha}^{\operatorname{sic}} \Delta t_{1}$ & $s_{\mathrm{ex}}^{\mathrm{asc}} \Delta t_{1}$ & $\begin{array}{l}0 \\
0\end{array}$ & $s_{\mathrm{n} \alpha}^{\mathrm{anc}} \Delta t_{2}$ & $s_{\mathrm{ee} \alpha}^{\mathrm{acs}} \Delta t_{2}$ & $\begin{array}{l}0 \\
0\end{array}$ & $\begin{array}{l}0 \\
s_{\mathrm{nn} \alpha}^{\mathrm{asc}} \Delta t_{3}\end{array}$ & $s_{\mathrm{ee} \alpha}^{\mathrm{acs}} \Delta t_{3}$ & $\begin{array}{l}0 \\
0\end{array}$ & & $\begin{array}{l}\alpha_{0-2}^{2} \\
\alpha_{2-4}^{0 \operatorname{sic}_{2}}\end{array}$ \\
\hline$s_{\mathrm{n} \rho}^{\mathrm{d} \rho} \Delta t_{0}$ & $s_{\mathrm{e} \rho}^{\mathrm{dsc}} \Delta t_{0}$ & $s_{\mathrm{v} \rho}^{\mathrm{dsc}} \Delta t_{0}$ & 0 & 0 & 0 & 0 & 0 & 0 & 0 & 0 & 0 & $\begin{array}{l}n \\
V_{\mathrm{e}}^{0}\end{array}$ & \\
\hline 0 & 0 & 0 & $s_{\mathrm{n} \rho}^{\mathrm{dsc}} \Delta t_{1}$ & $s_{\mathrm{e} \rho}^{\mathrm{dsc}} \Delta t_{1}$ & $s_{v \rho}^{\mathrm{dsc}} \Delta t_{1}$ & $s_{\mathrm{n} \rho}^{\mathrm{dsc}} \Delta t_{2}$ & $s_{\mathrm{e} \rho}^{\mathrm{dsc}} \Delta t_{2}$ & $s_{v \rho}^{\mathrm{dsc}} \Delta t_{2}$ & 0 & 0 & 0 & $V_{\mathrm{v}}^{0}$ & $\rho_{1-}^{\mathrm{ds}}$ \\
\hline 0 & 0 & 0 & 0 & 0 & 0 & 0 & 0 & 0 & $s_{n \rho}^{\mathrm{dsc}} \Delta t_{3}$ & $s_{\mathrm{e} \rho}^{\mathrm{dsc}} \Delta t_{3}$ & $s_{v \rho}^{\mathrm{dsc}} \Delta t_{3}$ & $V_{\mathrm{n}}^{1}$ & \\
\hline$s_{\mathrm{n} \alpha}^{\mathrm{dsc}} \Delta t_{0}$ & $s_{e \alpha \alpha}^{\mathrm{dsc}} \Delta t_{0}$ & 0 & 0 & 0 & 0 & 0 & 0 & 0 & 0 & 0 & 0 & $V_{\mathrm{e}_{1}}^{1}$ & \\
\hline 0 & 0 & 0 & $s_{\mathrm{n} \alpha}^{\mathrm{dsc}} \Delta t_{1}$ & $s_{\alpha \alpha}^{\mathrm{dsc}} \Delta t_{1}$ & 0 & $s_{\mathrm{n} \alpha}^{\mathrm{dsc}} \Delta t_{2}$ & $s_{\alpha \alpha}^{\mathrm{dsc}} \Delta t_{2}$ & 0 & 0 & 0 & 0 & $V_{\mathrm{v}}^{1}$ & $\alpha_{1-3}^{\mathrm{dsc}}$ \\
\hline 0 & 0 & 0 & 0 & 0 & 0 & 0 & 0 & 0 & $s_{\mathrm{n} \alpha}^{\mathrm{dcc}} \Delta t_{3}$ & $s_{\mathrm{e \alpha} \alpha}^{\mathrm{dcc}} \Delta t_{3}$ & 0 & $V_{n}^{2}$ & $\alpha_{3-4}^{\mathrm{d} s \mathrm{c}}$ \\
\hline$\lambda_{0}^{\lambda}$ & ${ }_{\lambda}^{0}$ & $\begin{array}{l}0 \\
0\end{array}$ & $-\lambda$ & $\begin{array}{c}0 \\
-\lambda\end{array}$ & $\begin{array}{l}0 \\
0\end{array}$ & ${ }_{0}^{0}$ & 0 & 0 & 0 & 0 & 0 & $V_{\mathrm{e}}^{2}$ & 0 \\
\hline 0 & $\lambda$ & 0 & 0 & $-\lambda$ & 0 & 0 & $\begin{array}{l}0 \\
0\end{array}$ & $\begin{array}{l}0 \\
0\end{array}$ & $\begin{array}{l}0 \\
0\end{array}$ & 0 & 0 & $V_{\mathrm{v}_{\mathrm{v}}}^{2}$ & 0 \\
\hline 0 & 0 & $\hat{0}$ & $\lambda$ & 0 & $\begin{array}{c}-\lambda \\
0\end{array}$ & $\begin{array}{c}0 \\
-\lambda\end{array}$ & 0 & 0 & 0 & 0 & 0 & $V_{n}^{3}$ & 0 \\
\hline 0 & 0 & 0 & 0 & $\lambda$ & 0 & 0 & $-\lambda$ & 0 & 0 & 0 & 0 & $V_{\mathrm{e}}^{3}$ & 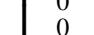 \\
\hline 0 & 0 & 0 & 0 & 0 & $\lambda$ & 0 & 0 & $-\lambda$ & 0 & 0 & 0 & $\backslash V_{\mathrm{v}}^{3}$ & $\begin{array}{l}0 \\
0 \\
0\end{array}$ \\
\hline 0 & 0 & 0 & 0 & 0 & 0 & $\lambda$ & 0 & 0 & $-\lambda$ & 0 & 0 & & \\
\hline 0 & 0 & 0 & 0 & 0 & 0 & 0 & $\lambda$ & 0 & 0 & $-\lambda$ & 0 & & 0 \\
\hline 0 & 0 & 0 & 0 & 0 & 0 & 0 & 0 & $\lambda$ & 0 & 0 & $-\lambda$ & & \\
\hline
\end{tabular}


The 3D flow displacement time series are then computed as in Eq. (1b) as $D_{\mathrm{n}, \mathrm{e}, \mathrm{v}}^{i+1}=D_{\mathrm{n}, \mathrm{e}, \mathrm{v}}^{i}+V_{\mathrm{n}, \mathrm{e}, \mathrm{v}}^{i} \Delta t_{i}$ for $i=\{0,1,2,3\}$, assuming that the initial displacements $D_{\mathrm{n}, \mathrm{e}, \mathrm{v}}^{0}$ are equal to zero. Note that in this notation $D_{\mathrm{n}, \mathrm{e}, \mathrm{v}}^{0}$ represents the 3D displacements at time $t_{0}$, while $V_{\mathrm{n}, \mathrm{e}, \mathrm{v}}^{0}$ and $\Delta t_{0}$ are the $3 \mathrm{D}$ velocities and the time interval at the time epoch $t_{0}-t_{1}$, thus effectively available at time $t_{1}$. For simplicity of presentation, a linear trend is computed by applying linear regression to the derived values, calculated over the entire record, to illustrate the 3D displacement time series and three linear rate maps used for visualizing the results. Note that in the case of non-steady-state flow, the linear rates, which are effectively mean linear rates, can significantly differ from the instantaneous flow velocities. Linear rates can potentially be computed over a time interval of any duration (for example, 1 month or 1 year).

Tikhonov regularizations of various orders can be applied during the inversion, resulting in temporal smoothing. The zeroth-order regularization is effectively the constant displacement constraint. The first-order regularization is effectively the constant velocity constraint, and the second-order regularization is effectively the constant acceleration constraint. The first- and second-order regularizations both produce good, virtually indistinguishable results. The example above in Eq. (3) uses first-order regularization. Zeroth- and second-order regularizations are explicitly shown in Samsonov and d'Oreye (2017) for the 2D case. The magnitude of smoothing is controlled by the regularization parameter $\lambda$ that can be selected, for example, using the L-curve method (Hansen and O'Leary, 1993; Samsonov and d'Oreye, 2017). We used a value of 0.1 for $\lambda$ selected using the L-curve method.

MSBAS methodology has been developed for computing multidimensional time series by combining multiple DInSAR data acquired at different times and in various observational geometries. The $2 \mathrm{D}$ (east and vertical) method was described in Samsonov and d'Oreye $(2012,2017)$ and the surface-parallel flow-constrained 3D (north, east, vertical) method in Samsonov (2019) and Samsonov et al. (2020). The unconstrained 3D method (i.e., without the surface-parallel flow constraint) presented here uses both range and azimuth measurements for computing 3D displacements. This work is now possible due to improved availability over large areas of high-quality, high-resolution, temporally dense ascending and descending SAR data and the increase in computational power that allows computing a large number of range and azimuth offset maps and inverting large matrices. Since this method does not make any assumptions about the direction of motion, it provides the optimal solution applicable to any surface motion (e.g., glacier flow, tectonic and anthropogenic deformation). The typical size of the transform matrix exceeds hundreds and often thousands of columns and rows for each pixel. It is $446 \times 666$ (or $1109 \times 666$ including regularization terms; in the following, for simplic- ity, matrix $L$ is assumed to be a part of matrix $A$ ) in our case. Thus, the total number of azimuth and range offset maps $M$ equals 446, and the number of unknowns $N$ equals 666 , which corresponds to 223 SLC images after applying the boundary correction. The additional $N-3=663$ rows represent the first-order Tikhonov regularization terms. The singular value decomposition (SVD) algorithm from the Linear Algebra PACKage (LAPACK) library is used for inverting this matrix for each pixel. Processing is parallelized using Open Multi-Processing (OpenMP) implementation of multithreading. Depending on the number of cores in the processing unit and the number of pixels, this process can take from several hours to several days. Processing time in our case, on a 44-core workstation is approximately $24 \mathrm{~h}$. The Message Passing Interface (MPI) version of the software has also been developed. The processing time in an MPI version is reduced proportionally to the number of nodes.

\subsection{Synthetic tests}

We used synthetic tests with the actual transform matrix $A$, which is described in detail in the next section, to demonstrate the effectiveness of the proposed technique. First, we reconstructed deformation components using the harmonic input signal in only one of the components, which is described in the respective legends in Fig. 2a-c. Then we added Gaussian noise and repeated the computations (Fig. 2d-f). The magnitude of the noise was computed as $10 \%$ of the average displacement between consecutive epochs. Second, we reconstructed deformation components using the complex partially uncorrelated input signal: harmonic (with a different period in all components) and linear input signals in the horizontal components and the harmonic signals in the vertical component. Three runs were performed with $0 \%, 10 \%$, and $30 \%$ Gaussian noise added (Fig. 3a-c). Third, we reconstructed deformation components using the complex correlated input signal: harmonic (with the same period in all components) and linear input signals in all three components. Three runs were performed, again with $0 \%, 10 \%$, and $30 \%$ Gaussian noise added (Fig. 3d-f).

Without added noise the reconstructed output signal is practically identical to the input signal; with added noise, the reconstructed signal still resembles the input signal very well. For a quantitative assessment, we computed correlation and covariance matrices between three vectors comprising east, north, and vertical components of velocity at each observation epoch. Six correlation and covariance matrices are presented in Table 2 for each of six tests shown in Fig. 3. Both matrices provide valuable information about the quality of reconstruction.

In the covariance matrices, diagonal elements are variances of north, east, and vertical components of the velocity. They reflect variability due to a true signal and noise. Potentially, an input model can be subtracted to compute variances due to noise; however, it is not a goal of this test. Instead, 

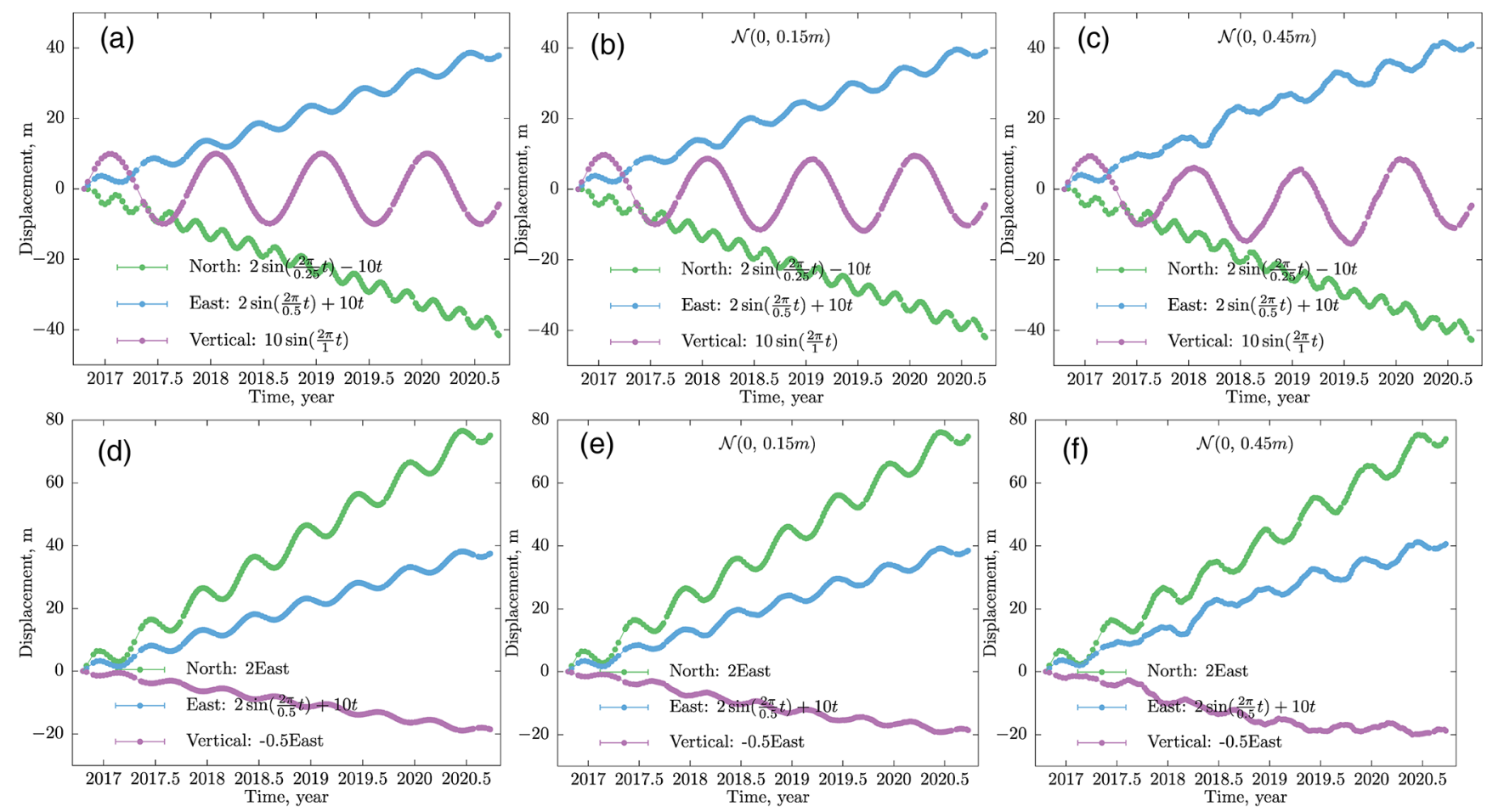

Figure 3. Results of numerical simulations demonstrating the ability of this technique to reconstruct complex uncorrelated and correlated input signals in all three components. Equations of input signals are shown in corresponding subfigure legends; $t$ is time. Harmonic and linear input signals are assumed. Gaussian noise with a mean value of zero and standard deviations in the range $0.15-0.45 \mathrm{~m}$ (which is approximately $10 \%-30 \%$ of the signal) is added to subfigures in the second and third columns.

Table 1. Sentinel-1 SAR data used in this study; $\theta$ is incidence and $\phi$ is azimuth angle.

\begin{tabular}{|c|c|c|c|c|}
\hline & Span & $\theta^{\circ}$ & $\phi^{\circ}$ & Number of SLC swaths \\
\hline Sentinel-1 track 123 (asc) & 16 August 2016-28 January 2021 & 39 & 342 & 109 \\
\hline Sentinel-1 track $116(\mathrm{dsc})$ & 20 October 2016-21 January 2021 & 39 & 198 & 116 \\
\hline Total (after boundary correction) & 20 October 2016-20 January 2021 & & & 223 \\
\hline
\end{tabular}

we are interested in covariance (i.e., non-diagonal) terms of the covariance matrix. They are expected to be small (comparable) in comparison to diagonal terms in the case of the uncorrelated (correlated) signal. In the correlation matrices, it is expected that non-diagonal terms should be small (close to one) in the case of the uncorrelated (correlated) signal. Indeed, this pattern is clearly observed in both cases of uncorrelated (Table 2a-c) and correlated (Table 2d-f) signals.

Overall these tests indicate that the ascending-descending geometry is sufficient for a full reconstruction of 3D motion. This can also be inferred theoretically by computing a rank of the transform matrix in the case of one ascending and one descending pair acquired at the same time, which would be equal to 3 .

\section{Study area and data}

Southeastern Alaska has experienced significant ice mass loss and retreat over the last 50 years (Arendt et al., 2009; Arendt, 2011). Of the 27000 glaciers that occupy the region, the majority $(99.8 \%$ ) are land-terminating (RGI Consortium, 2017). Consequently, monitoring the mass balance and ice dynamic variations of Alaska's land-terminating glaciers is paramount for the future of its landscape and resultant contributions to sea level rise (Larsen et al., 2015). Unlike the plethora of ice velocity data products available for Greenland and Antarctica, regional studies of Alaskan glacier surface velocities are less abundant. The first regional map of Alaskan glacier flow velocities was released in 2013 using ALOS PALSAR data (Burgess et al., 2013). Soon after, feature tracking of Landsat optical data began to regularly map regional surface velocities (Fahnestock et al., 2015; Gardner et al., 2018, 2019). Recent studies demonstrate the im- 
Table 2. Correlation (first matrix in cell) and covariance (second matrix in cell) matrices of north, east, and vertical components of velocity for six synthetic tests shown in Fig. 3. Labels (a)-(f) correspond to subfigures in Fig. 3. Columns are in order - north, east, vertical. Units of covariance matrix terms are $\left(\mathrm{m} \mathrm{yr}^{-1}\right)^{2}$.

\begin{tabular}{|c|c|c|c|c|c|c|c|c|c|c|c|c|c|c|c|c|c|}
\hline \multicolumn{6}{|c|}{ (a) } & \multicolumn{6}{|c|}{ (b) } & \multicolumn{6}{|c|}{ (c) } \\
\hline$\left(\begin{array}{c}1.000 \\
-0.087 \\
-0.083\end{array}\right.$ & $\begin{array}{c}-0.087 \\
1.000 \\
-0.040\end{array}$ & $\begin{array}{l}-0.083 \\
-0.040 \\
1.000\end{array}$ & $\left(\begin{array}{c}0.470 \\
-0.023 \\
-0.052\end{array}\right.$ & $\begin{array}{c}-0.023 \\
0.143 \\
-0.014\end{array}$ & $\left.\begin{array}{c}-0.052 \\
-0.014 \\
0.846\end{array}\right)$ & $\left(\begin{array}{c}1.000 \\
-0.084 \\
-0.081\end{array}\right.$ & $\begin{array}{c}-0.084 \\
1.000 \\
-0.080\end{array}$ & $\begin{array}{c}-0.081 \\
-0.080 \\
1.000\end{array}$ & $\left(\begin{array}{c}0.465 \\
-0.022 \\
-0.051\end{array}\right)$ & $\begin{array}{c}-0.022 \\
0.151 \\
-0.029\end{array}$ & $\left.\begin{array}{c}-0.051 \\
-0.029 \\
0.847\end{array}\right)$ & $\left(\begin{array}{c}1.000 \\
-0.069 \\
-0.073\end{array}\right.$ & $\begin{array}{c}-0.069 \\
1.000 \\
-0.140\end{array}$ & $\begin{array}{c}-0.073 \\
-0.140 \\
1.000\end{array}$ & $\left(\begin{array}{c}0.486 \\
-0.021 \\
-0.047\end{array}\right.$ & $\begin{array}{c}-0.021 \\
0.201 \\
-0.059\end{array}$ & $\begin{array}{c}-0.047 \\
-0.059 \\
0.877\end{array}$ \\
\hline \multicolumn{6}{|c|}{ (d) } & \multicolumn{6}{|c|}{ (e) } & \multicolumn{6}{|c|}{ (f) } \\
\hline$\left(\begin{array}{c}1.000 \\
0.999 \\
-0.997\end{array}\right.$ & $\begin{array}{c}0.999 \\
1.000 \\
-0.995\end{array}$ & $\begin{array}{c}-0.997 \\
-0.995 \\
1.000\end{array}$ & $\left(\begin{array}{c}0.581 \\
0.287 \\
-0.145\end{array}\right.$ & $\begin{array}{c}0.287 \\
0.142 \\
-0.072\end{array}$ & $\left.\begin{array}{c}-0.145 \\
-0.072 \\
0.036\end{array}\right)$ & $\left(\begin{array}{c}1.000 \\
0.975 \\
-0.937\end{array}\right.$ & $\begin{array}{c}0.975 \\
1.000 \\
-0.923\end{array}$ & $\begin{array}{c}-0.937 \\
-0.923 \\
1.000\end{array}$ & $\left(\begin{array}{c}0.594 \\
0.290 \\
-0.151\end{array}\right.$ & $\begin{array}{c}0.290 \\
0.149 \\
-0.075\end{array}$ & $\left.\begin{array}{c}-0.151 \\
-0.075 \\
0.044\end{array}\right)$ & $\left(\begin{array}{c}1.000 \\
0.824 \\
-0.681\end{array}\right.$ & $\begin{array}{c}0.824 \\
1.000 \\
-0.618\end{array}$ & $\begin{array}{c}-0.681 \\
-0.618 \\
1.000\end{array}$ & $\left(\begin{array}{c}0.653 \\
0.297 \\
-0.162\end{array}\right.$ & $\begin{array}{c}0.297 \\
0.199 \\
-0.081\end{array}$ & $\begin{array}{c}-0.162 \\
-0.081 \\
0.087\end{array}$ \\
\hline
\end{tabular}

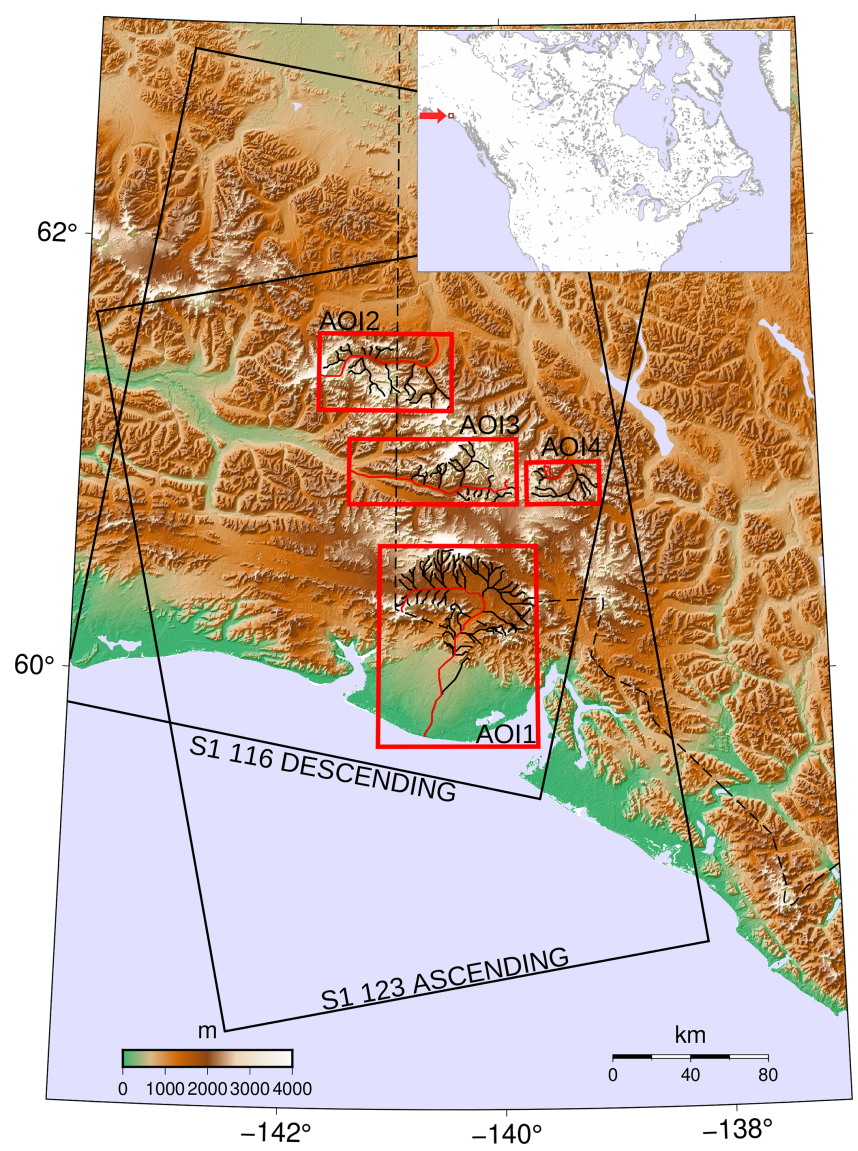

Figure 4. Outlines of four areas of interest (AOIs) in southeastern Alaska are shown in red. AOI1 covers Agassiz (AG), Malaspina (MG), and Seward (SG) glaciers. AOI2 covers Klutlan Glacier (KG). AOI3 covers Walsh Glacier (WG). AOI4 covers Kluane Glacier. Flow lines in black and red were computed using Open Global Glacier Model (OGGM) software (Maussion et al., 2019). Outlines of ascending (track 123) and descending (track 116) Sentinel-1 swaths are shown in black. The background is the $30 \mathrm{~m}$ Advanced Spaceborne Thermal Emission and Reflection Radiometer (ASTER) digital elevation model (Abrams et al., 2020). The Canada-US border is shown as a dashed black line.

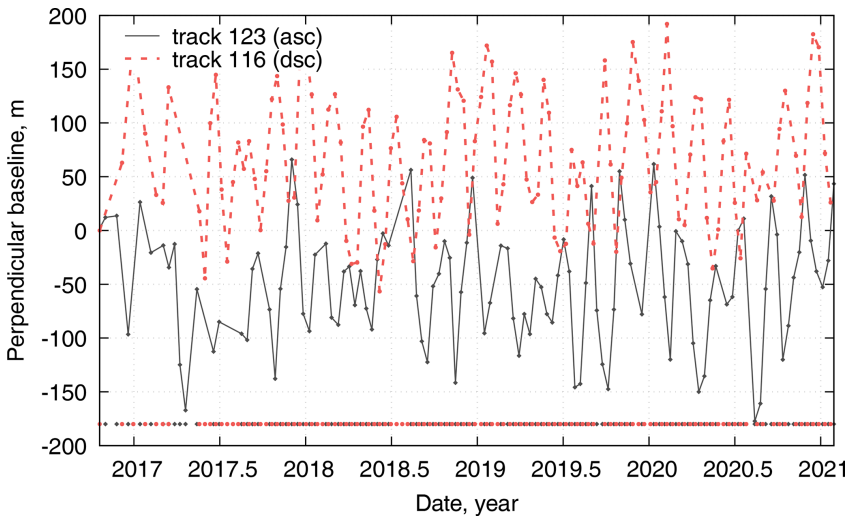

Figure 5. Spatial and temporal baselines of Sentinel-1 pairs used in this study. Mean temporal resolution, i.e., mean temporal spacing between consecutive SAR acquisitions regardless of orbit direction, computed as duration divided by the number of SAR images $(4.25$ years $\times 365 / 223)$ is about $7 \mathrm{~d}$. Note that the offset between ascending and descending sets depends on the selection of reference images, which is arbitrary.

portance of characterizing the temporal evolution of glacier surface flow for understanding changes in ice dynamics in Alaska (Waechter et al., 2015; Altena et al., 2019). However, all regional studies of Alaskan glacier flow have so far been limited to two dimensions, thus ignoring an important vertical component of flow, which links glacier surface elevation change and its mass balance. Here, we introduce a technique to generate a dense record of regional Alaskan glacier surface flow in three dimensions.

We focus on studying the dynamic changes along six landterminating glaciers in southeastern Alaska during 20 October 2016-21 January 2021: Agassiz, Seward, Malaspina, Klutlan, Kluane, and Walsh glaciers (Fig. 4). The Malaspina Glacier is the world's largest piedmont glacier covering approximately $2200 \mathrm{~km}^{2}$ on the flat coastal foreland (Sharp, 1958; Muskett et al., 2003; Sauber et al., 2005) and is partially fed by Seward Glacier, a surge-type glacier that originates in the upper reaches of Mt. Logan (Sharp, 1951; Ford et al., 2003). A mass budget deficit in the Malaspina-Seward complex has long been recognized (Sharp, 1951). Agassiz Glacier is another surge-type glacier that flows in an adja- 


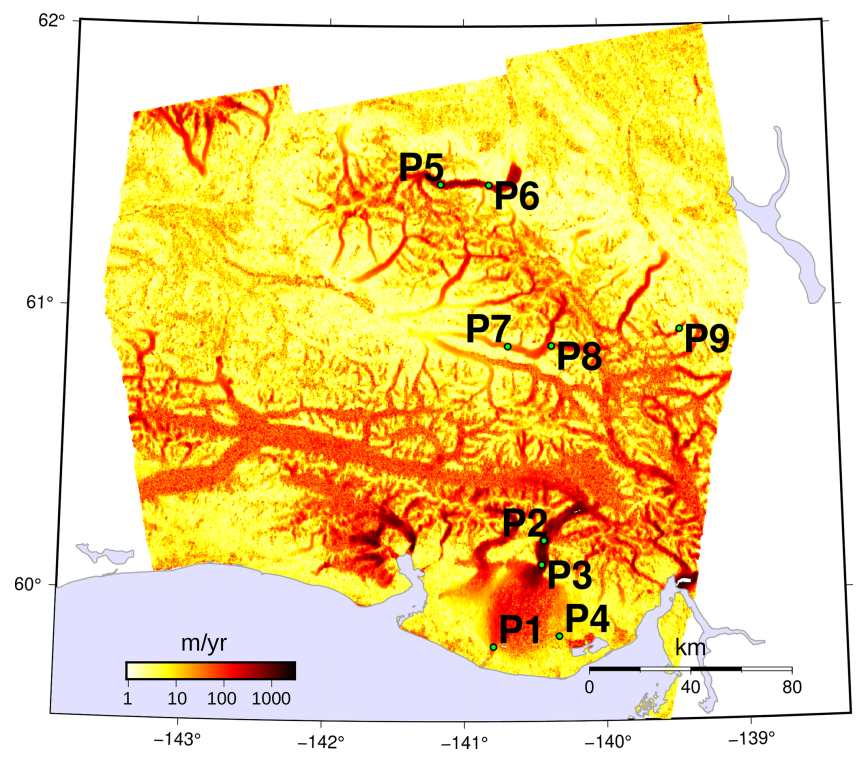

Figure 6. Magnitude of mean 3D flow velocities plotted using logarithmic scale. For regions $\mathrm{P} 1-\mathrm{P} 4$ at Malaspina and Seward glaciers, P5-P6 at Klutlan Glacier, P7-P8 at Walsh Glacier, and P9 at Kluane Glacier time series are provided in Figs. 11 and 12.

cent sinuous valley northwest of the Malaspina-Seward complex (Muskett et al., 2003; Sauber et al., 2005). The Klutlan Glacier is an $82 \mathrm{~km}$ long surge-type valley glacier located at elevations between 1300 and $2100 \mathrm{~m}$; it has surged repeatedly over the last few hundred years (Wright, 1980; Driscoll, 1980). A surge at Kluane Glacier in the eastern St. Elias Mountains during 2017/18 was previously reported in Main et al. (2019). Walsh Glacier is a $90 \mathrm{~km}$ long surge-type valley glacier located at a higher elevation of about 1500-3000. It is fed by two major branches, one from the north and one from the east, and it converges with the Logan Glacier downstream (Fu and Zhou, 2020).

In this study, we used 218 ascending (track 123) and 232 descending (track 116) Sentinel-1 interferometric wide (IW) single-look complex (SLC) images with $2.3 \mathrm{~m}$ (range) $\times 14.9 \mathrm{~m}$ (azimuth) spatial resolution from the NASA Distributed Active Archive Center (DAAC) operated by the Alaska Satellite Facility (ASF) (Table 1). Two ascending and two descending frames along the azimuth directions were concatenated for each, resulting in 109 and 116 swaths, respectively. Ascending and descending sets were processed individually using GAMMA software (Wegmuller and Werner, 1997) that produced range and azimuth offsets for consecutive pairs (Fig. 5). To compute offsets, we used a $64 \times 16$ pixel sampling interval (or approximately $200 \times 200 \mathrm{~m}$ ) and a square $128 \times 128$ pixel (or approximately $400 \times 1600 \mathrm{~m}$ ) correlation window. Such a large window was required to obtain a distinct, statistically significant peak of the $2 \mathrm{D}$ cross-correlation function; its square shape produced similar precision in range and azimuth directions in radar co- ordinates and azimuth precision 4 times coarser than range precision in geocoded products. Note that the correlation window is not uniform, with larger weights given to the pixel in the center of the window. While the estimation of spatial resolution resulting from a nonuniform weighting of the pixel is beyond the scope of this study, the initial tests suggest that the spatial resolution is significantly better than the window size, which is also confirmed by the developers of GAMMA software (GAMMA Remote Sensing, personal communication, 20 January 2021). Offsets were spatially filtered using a Gaussian filter with a $1.3 \mathrm{~km}$ (6-sigma) filter width, geocoded using the TerraSAR-X $90 \mathrm{~m}$ digital elevation model (DEM) and resampled to a common grid with a ground spacing of $200 \mathrm{~m}$. Using Gaussian weights for filtering proved to be particularly beneficial as the filter produced satisfactory results for small and large glaciers. Filter width was chosen experimentally for our study but may be suboptimal in other regions.

\section{Results}

The magnitude of the mean 3D linear flow velocities plotted for the entire region using a logarithmic scale is shown in Fig. 6. An in-depth analysis was further performed for four small areas of interest (AOI1, AOI2, AOI3, and AOI4 in Fig. 4) shown in detail in Figs. 7-10. The flow lines in Fig. 4 were computed using the Open Global Glacier Model (OGGM) software (Maussion et al., 2019), and the central flow lines were chosen for in-depth analysis. Note that these flow lines are approximated to the actual glacier flow pattern. They are, however, computed in a consistent and repeatable way. In addition, time series sampled from $5 \times 5$ pixel regions along Malaspina and Seward glaciers (P1-P4), the Klutlan Glacier (P5-P6), Walsh Glacier (P7-P8), and Kluane Glacier (P9) are provided in Figs. 11 and 12.

For each AOI, the SAR backscatter intensity images show the six glaciers in detail: Agassiz, Malaspina, and Seward (AG, MG, and SG; Fig. 7a), Klutlan (KtG; Fig. 8a), Walsh (WG; Fig. 9a), and Kluane (KnG; Fig. 10a) glaciers. For five of these glaciers (excluding the Agassiz Glacier) velocities are sampled along flow lines with $20 \mathrm{~km}$ markers shown. Mean flow velocities are shown in Figs. 7b, 8b, 9b, and 10b; horizontal flow velocities are shown as vectors and vertical flow velocities are color-coded, with red representing downward motion. For aesthetic purposes, horizontal flow vectors are resampled to a coarser resolution. The fastest horizontal flow velocity exceeds $1000 \mathrm{myr}^{-1}$, and the fastest vertical flow velocity exceeds $200 \mathrm{~m} \mathrm{yr}^{-1}$. Overall, Seward Glacier experiences the fastest motion and Malaspina Glacier experiences the slowest motion (Fig. 7b); vertical flow is predominately downward along both glaciers. In contrast, vertical flow along the Klutlan (Fig. 8b), Walsh (Fig. 9b), and Kluane (Fig. 10b) glaciers changes direction a number of times. 


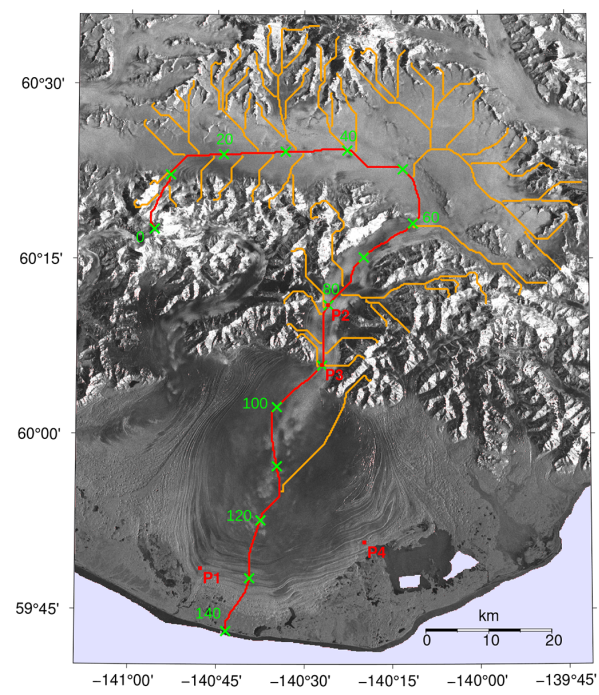

(a)

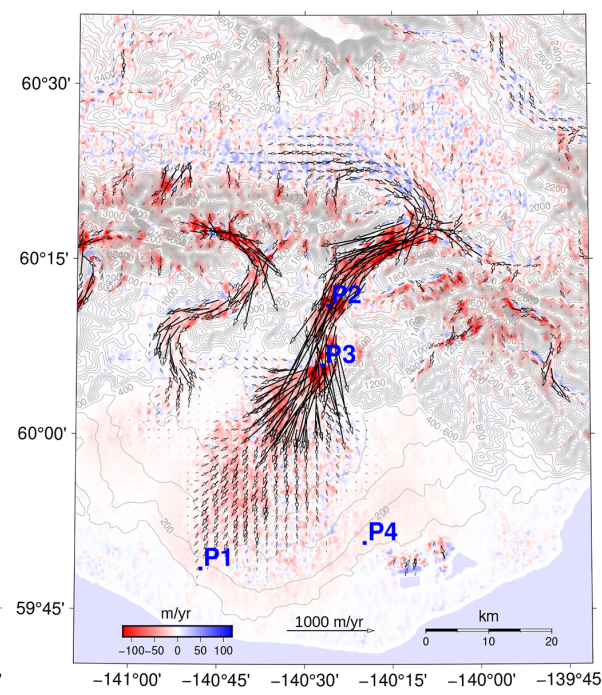

(b)
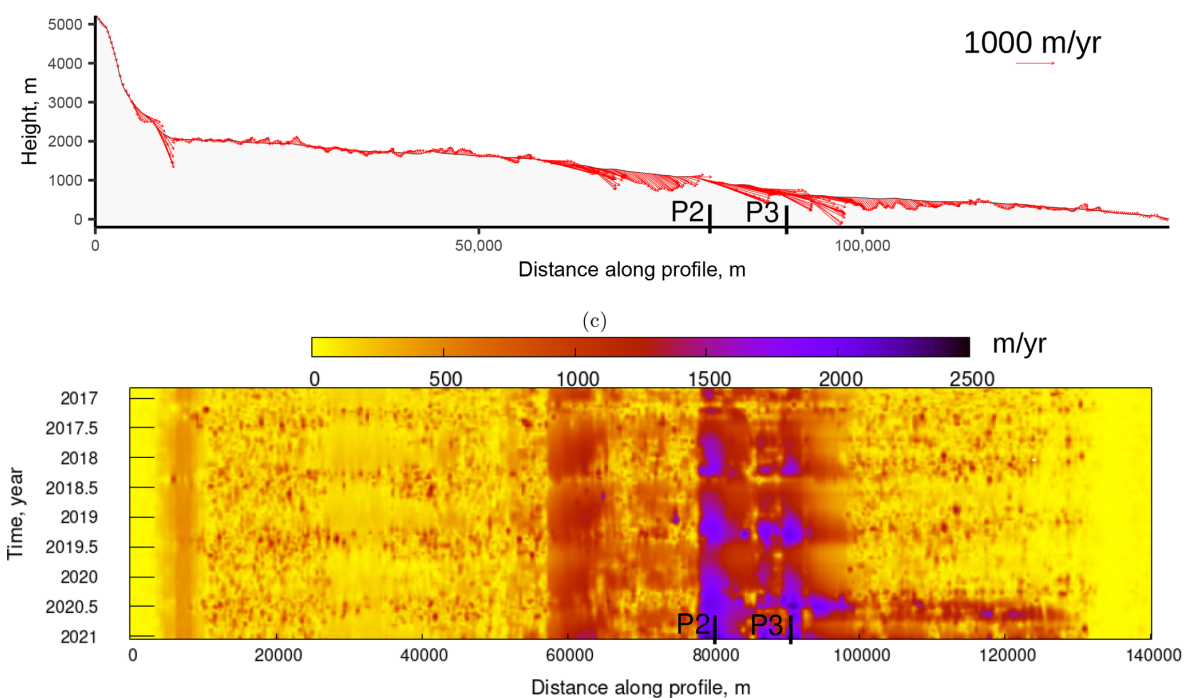

(d)

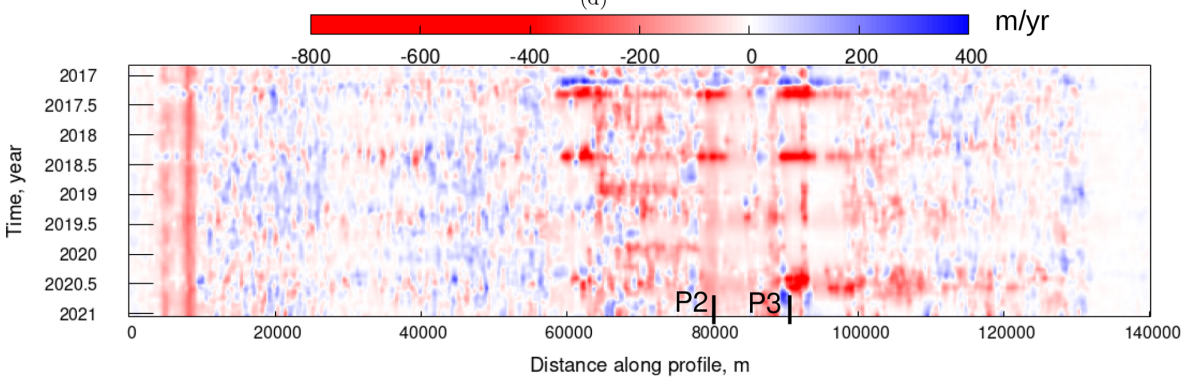

(e)

Figure 7. (a) Sentinel-1 SAR intensity image acquired on 22 December 2019 (in YYYYMMDD format) over AOI1 that covers Agassiz (AG), Malaspina (MG), and Seward (SG) glaciers. Flow lines are in orange and red. Markers in green show the distance in kilometers along the selected red flow line. (b) Time-averaged 3D flow velocities: horizontal velocity is shown as a (coarse-resolution) vector map, and vertical velocity is color-coded. Surface topographic contour lines derived from the TerraSAR-x $90 \mathrm{~m}$ DEM with intervals of $100 \mathrm{~m}$ are shown in gray. Flow displacement time series for regions P1-P4 are plotted in Fig. 11. (c) Time-averaged 3D flow velocities and glacier height along the red flow line. (d) Temporal evolution of horizontal flow velocity magnitude along the red flow line. (e) Temporal evolution of vertical flow velocity along the red flow line. 


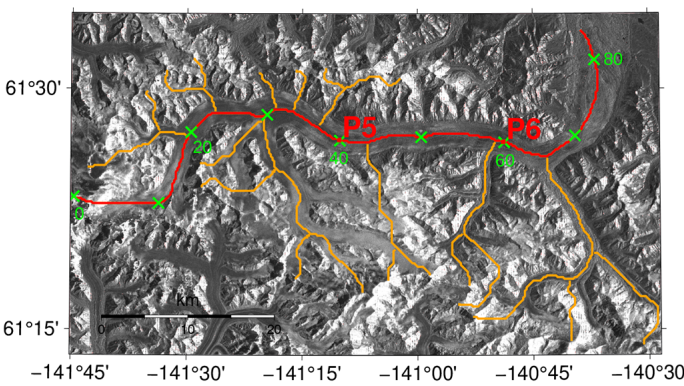

(a)

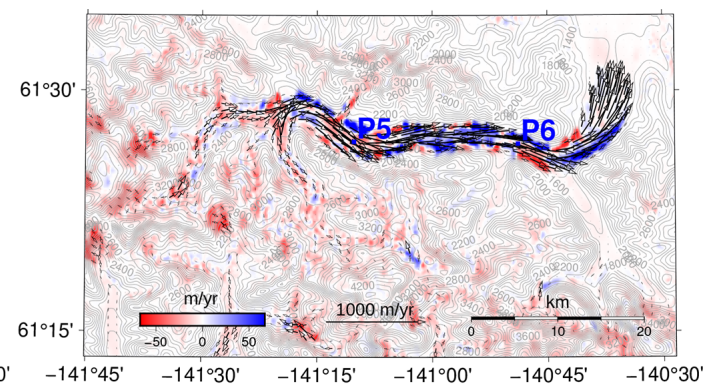

(b)

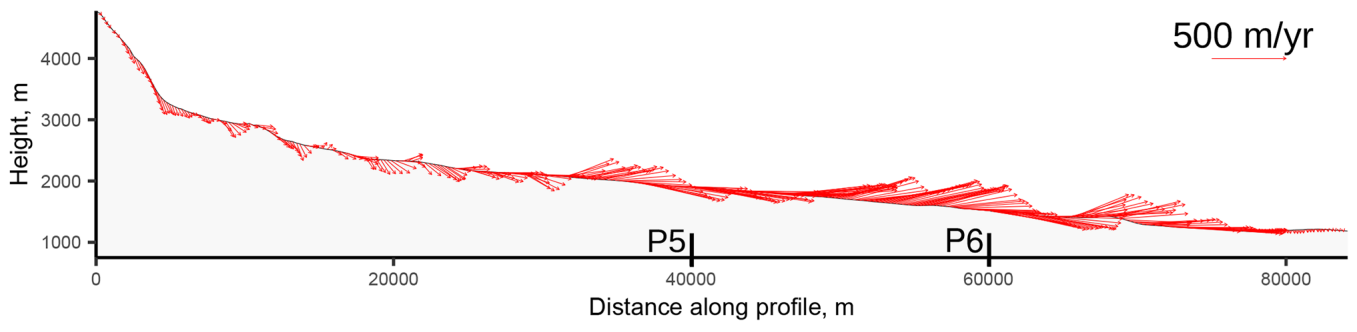

(c)
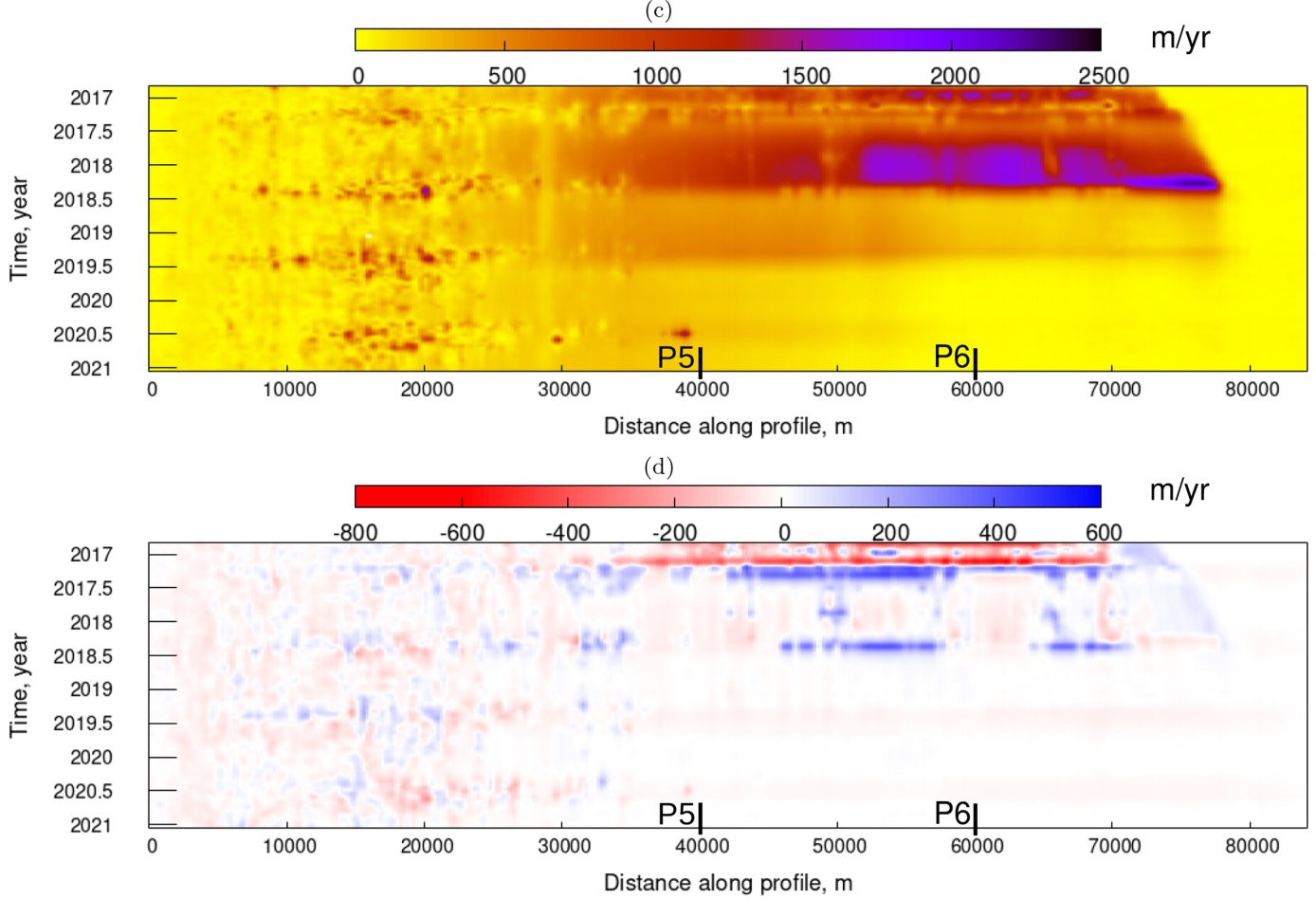

(e)

Figure 8. (a) Sentinel-1 SAR intensity image acquired on 22 December 2019 over AOI2 that covers Klutlan Glacier (KtG). Flow lines are in orange and red. Markers in green show the distance in kilometers along the selected red flow line. (b) Time-averaged 3D flow velocities: horizontal velocity is shown as a (coarse-resolution) vector map, and vertical velocity is color-coded. Surface topographic contour lines derived from the TerraSAR-x $90 \mathrm{~m}$ DEM with intervals of $100 \mathrm{~m}$ are shown in gray. Flow displacement time series for regions P5-P6 are plotted in Fig. 11. (c) Time-averaged 3D flow velocities and glacier height along the red flow line. (d) Temporal evolution of horizontal flow velocity magnitude along the red flow line. (e) Temporal evolution of vertical flow velocity along the red flow line. 


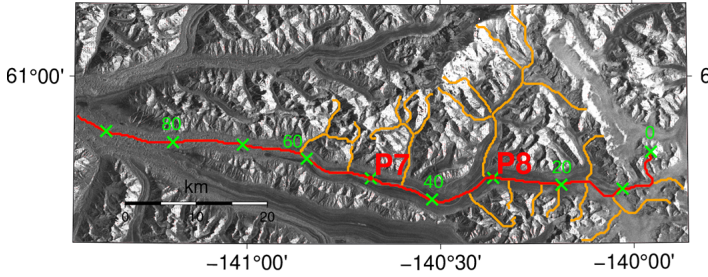

(a)

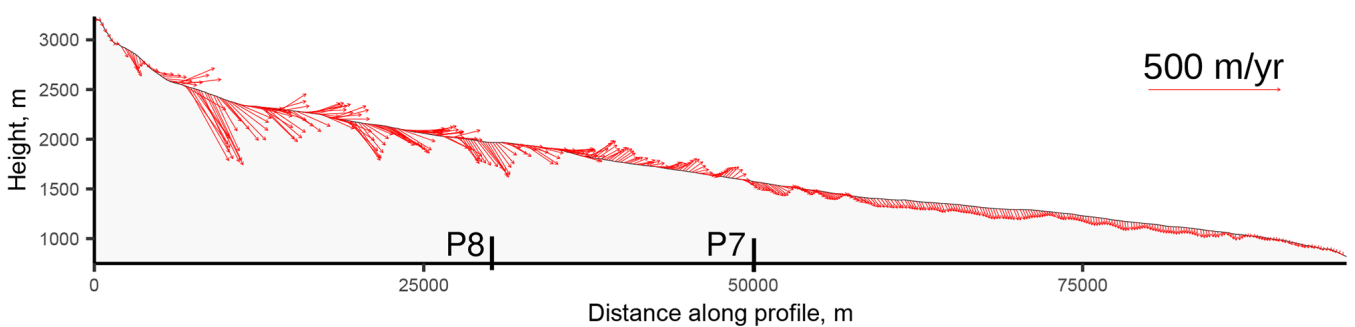

(c)

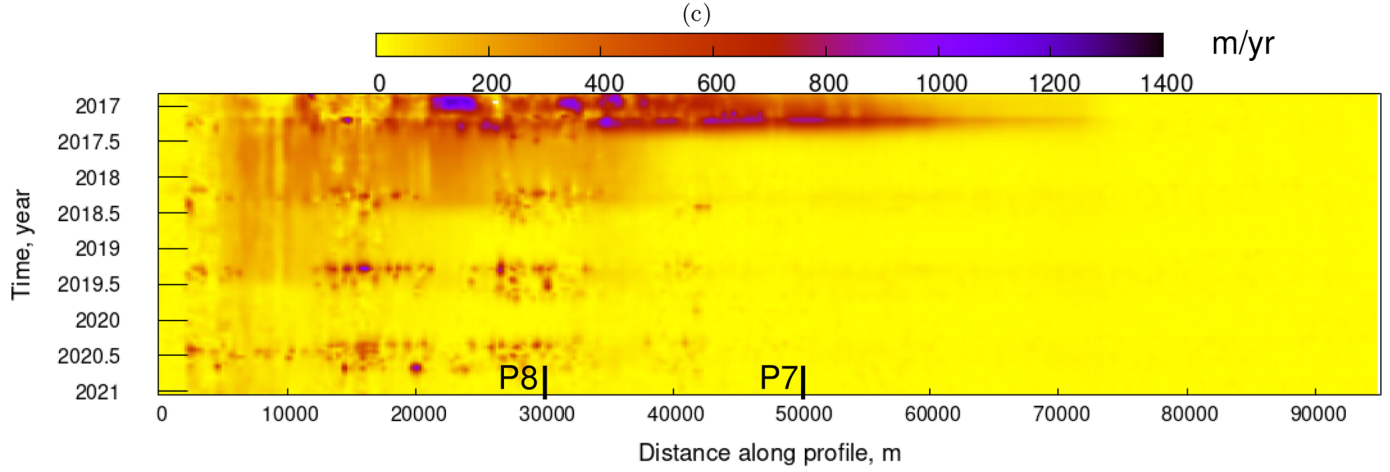

(d)

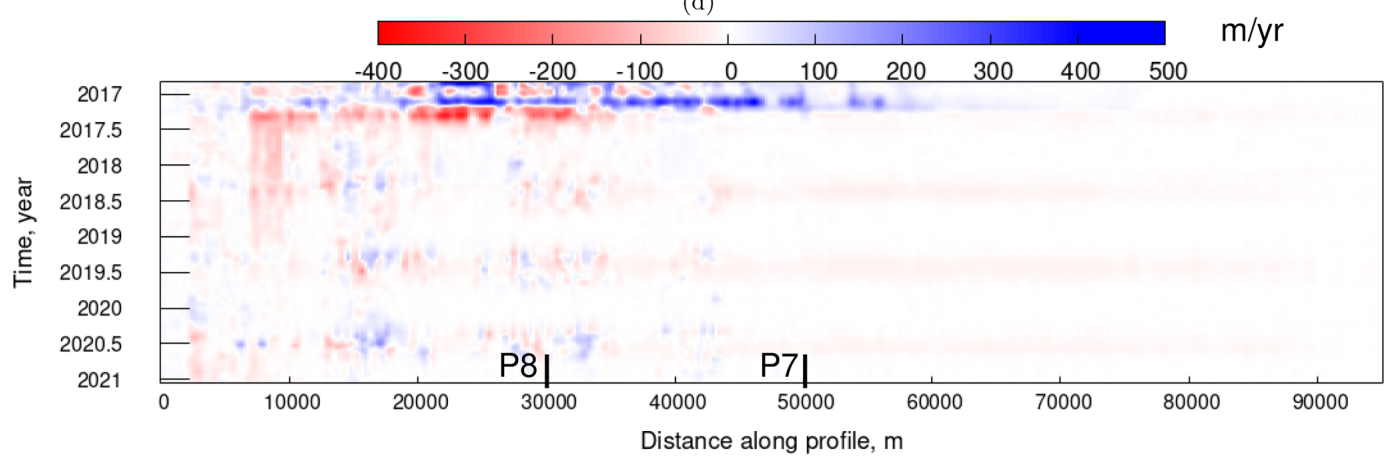

(e)

Figure 9. (a) Sentinel-1 SAR intensity image acquired on 22 December 2019 over AOI3 that covers Walsh Glacier (WG). Flow lines are in orange and red. Markers in green show the distance in kilometers along the selected red flow line. (b) Time-averaged 3D flow velocities: horizontal velocity is shown as a (coarse-resolution) vector map, and vertical velocity is color-coded. Surface topographic contour lines derived from the TerraSAR-x $90 \mathrm{~m}$ DEM with intervals of $100 \mathrm{~m}$ are shown in gray. Flow displacement time series for regions P7-P8 are plotted in Fig. 11. (c) Time-averaged 3D flow velocities and glacier height along the red flow line. (d) Temporal evolution of horizontal flow velocity magnitude along the red flow line. (e) Temporal evolution of vertical flow velocity along the red flow line.

The direction and magnitude of the mean linear flow velocities sampled along central flow lines from Malaspina and Seward, Klutlan, Walsh, and Kluane glaciers are shown in Figs. $7 \mathrm{c}, 8 \mathrm{c}, 9 \mathrm{c}$, and $10 \mathrm{c}$ as vectors with tails that start at the surface elevation of each glacier. Animations of these flow velocities as time series along these profiles are also provided in the Supplement. Note that the vertical axis (surface elevation) and horizontal axis (distance along profile) are scaled differently, producing significant but equal angular distortion in the flow velocities and topographic slopes. The mean linear flow velocities provide insight into the direction and magnitude of mean velocities calculated over a specific interval 


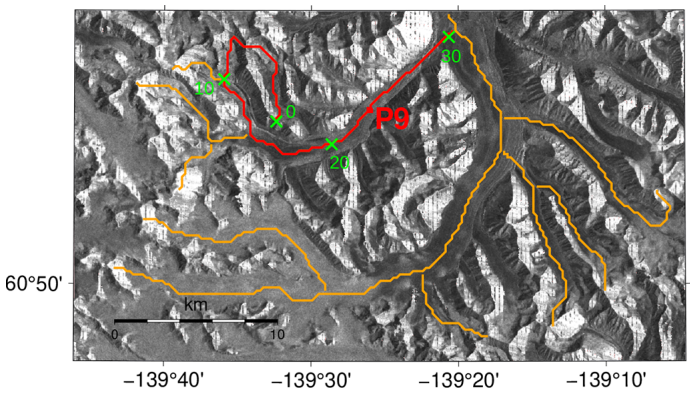

(a)

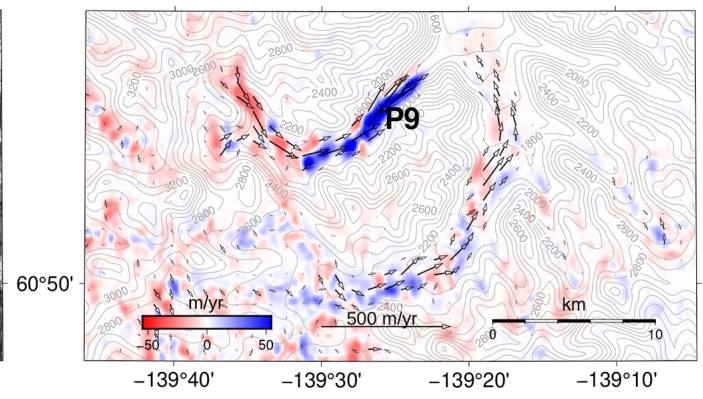

(b)

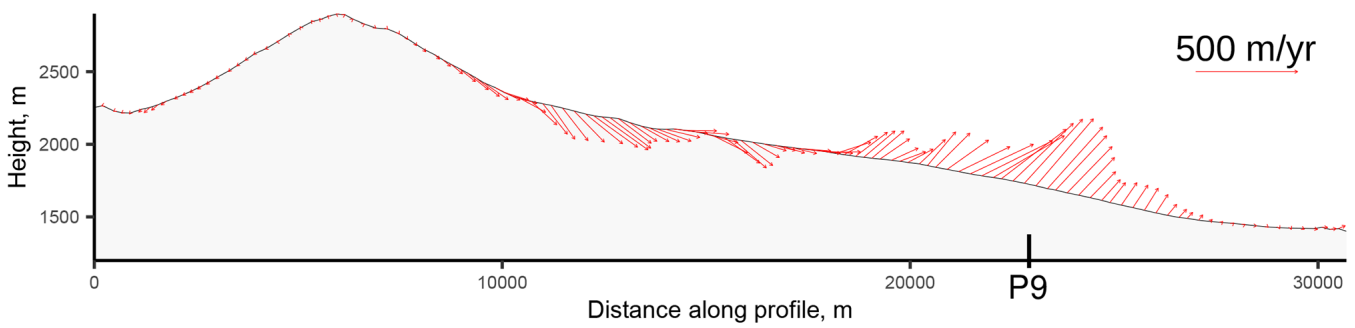

(c)

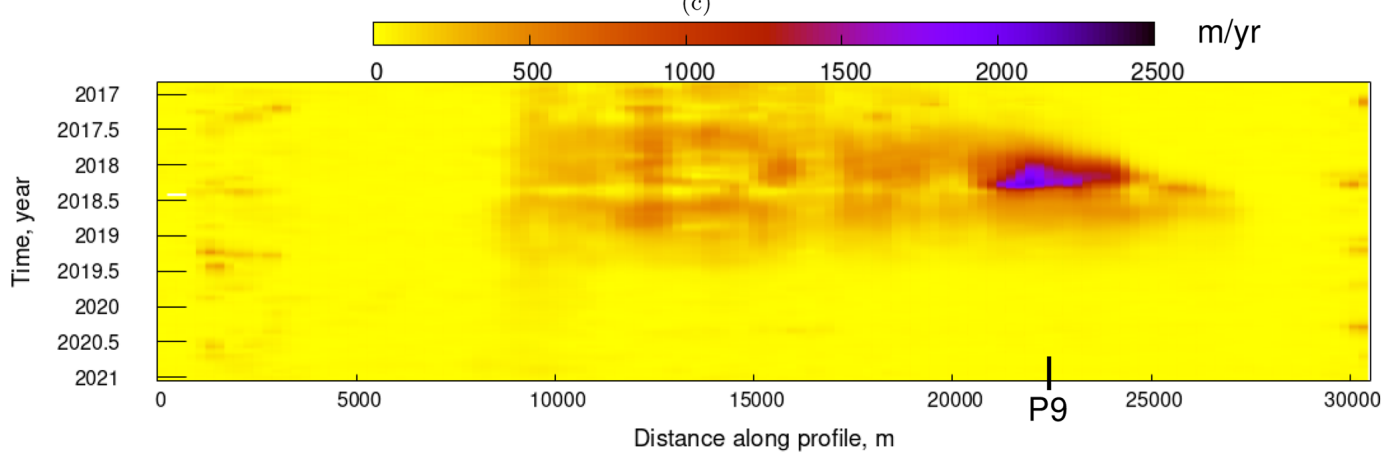

(d)

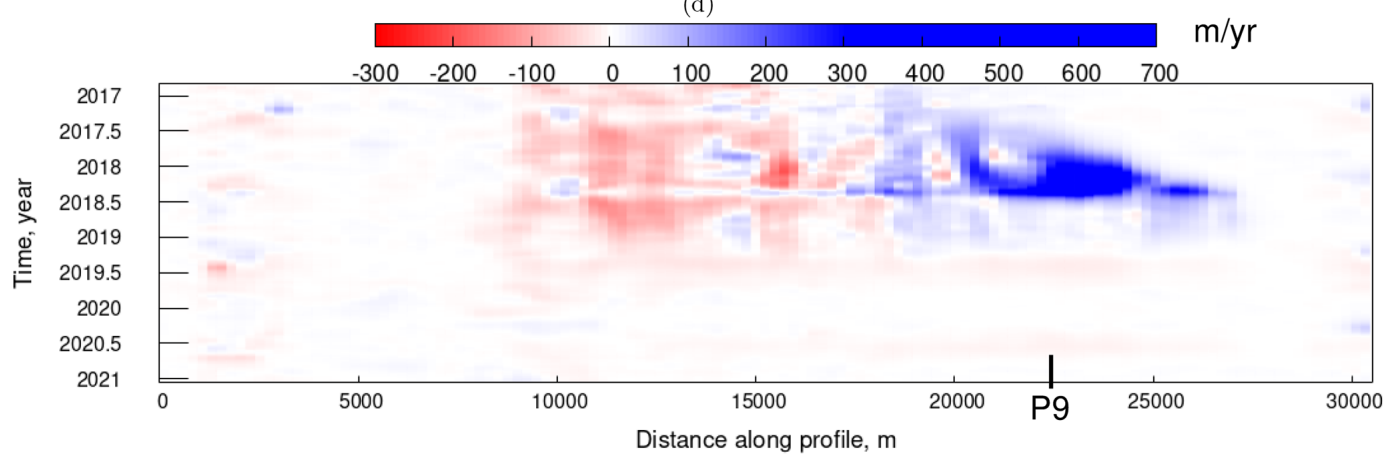

(e)

Figure 10. (a) Sentinel-1 SAR intensity image acquired on 22 December 2019 over AOI4 that covers Kluane Glacier (KnG). Flow lines are in orange and red. Markers in green show the distance in kilometers along the selected red flow line. (b) Time-averaged 3D flow velocities: horizontal velocity is shown as a (coarse-resolution) vector map, and vertical velocity is color-coded. Surface topographic contour lines derived from the TerraSAR-x $90 \mathrm{~m}$ DEM with intervals of $100 \mathrm{~m}$ are shown in gray. Flow displacement time series for region P9 are plotted in Fig. 11. (c) Time-averaged 3D flow velocities and glacier height along the red flow line. (d) Temporal evolution of horizontal flow velocity magnitude along the red flow line. (e) Temporal evolution of vertical flow velocity along the red flow line. 


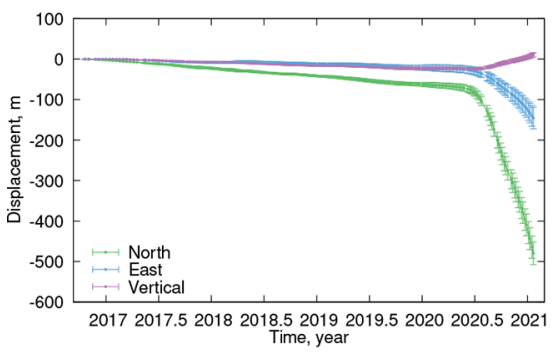

(a) P1

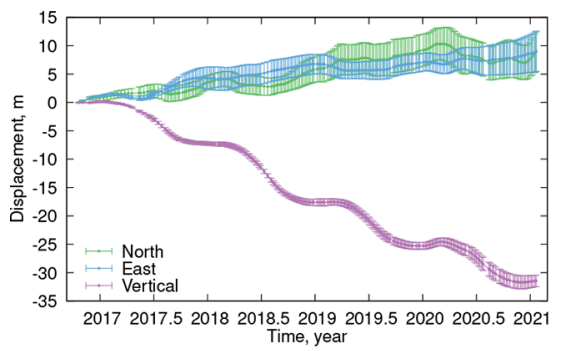

(d) P4

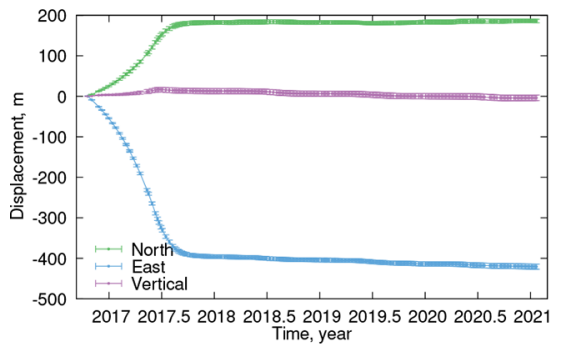

(g) P7

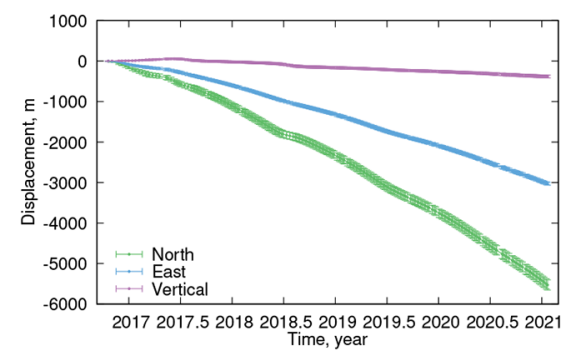

(b) P2

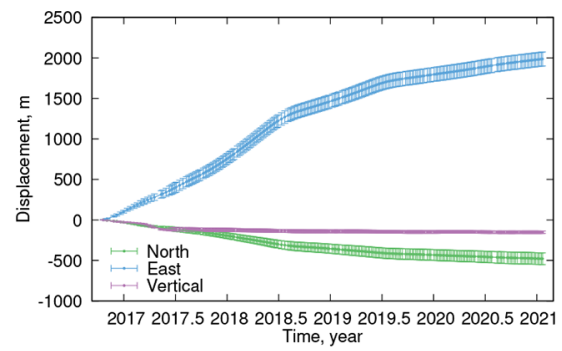

(e) P5

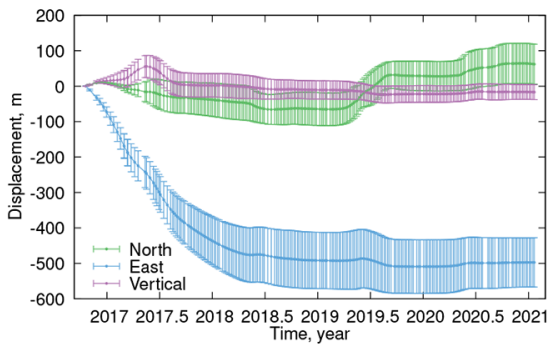

(h) P8

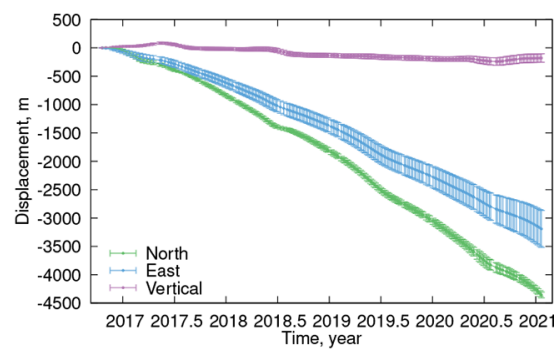

(c) P3

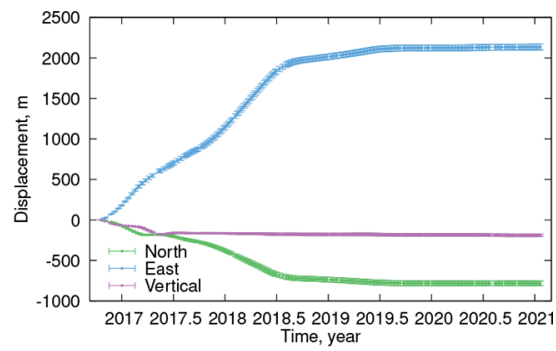

(f) P6

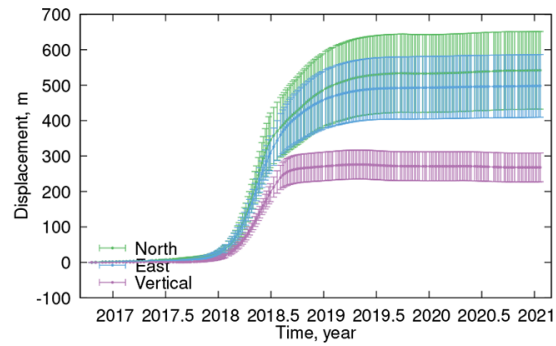

(i) P9

Figure 11. 3D flow displacement time series for regions P1-P9, the locations of which are shown in Figs. 6-10.

(e.g., the Sentinel-1 record); however, these values can vary over time. This is evident in the temporal evolution of the horizontal velocity magnitude and vertical velocity sampled along these profiles for the Seward and Malaspina glaciers (Fig. 7d and e), the Klutlan Glacier (Fig. 8d and e), the Walsh Glacier (Fig. 9d and e), and the Kluane Glacier (Fig. 10d and e). Flow along the lower reaches of the Malaspina Glacier varies seasonally, although the seasonal acceleration was delayed in 2020 and was higher in magnitude. Seasonal flow along the Klutlan, Walsh, and Kluane glaciers is far less pronounced; however, each shows an episodic shift in a flow that occurred around mid-2018, mid-2017, and mid-2018, respectively.

Examples of 3D flow displacement and velocity time series for the $5 \times 5$ pixel regions P1-P9 are shown in Figs. 11 and 12 . Similar time series can be easily produced for any colored pixel in Fig. 6; the locations selected were chosen to demonstrate diverse ice dynamic observations possible with the MSBAS-3D method. Regions P1 and P4 are located on the lower lobes of the Malaspina Glacier at an elevation of about 200 ma.s.l. The displacement time series show that flow is predominately west-southwest at P1 and northeast at
$\mathrm{P} 4$. An abrupt change in a flow regime occurred at P1 at the end of June 2020. Since then, the flow velocity at P1 has remained elevated in comparison to the values observed in prior years. This many-fold velocity increase can also be observed in Fig. 7d and e along the latter part of the profile. Horizontal and vertical flow velocities in these regions are only a few meters per year, with a seasonal signal evident at P4 in the vertical component. Such seasonal signals are observed at most low-elevation glaciers. Regions P2 and P3 are located at elevations of about 1000 and $700 \mathrm{~m}$. At these locations, horizontal flow dominates flow displacement, while vertical flow displacement is minimal. The southwest direction of flow is persistent at both locations. Flow velocities along the main branch of the Agassiz Glacier (not shown) are very similar to the flow velocities along the Seward Glacier but of a lesser magnitude.

Regions P5 and P6 are located on Klutlan Glacier at elevations of about 1900 and $1500 \mathrm{~m}$, respectively. The overall vertical flow is slightly downward in these regions, but horizontal and vertical components both show significant variability over time. Regions P7 and P8 are located on Walsh Glacier at an elevation of about 1700 and $2000 \mathrm{~m}$, respec- 


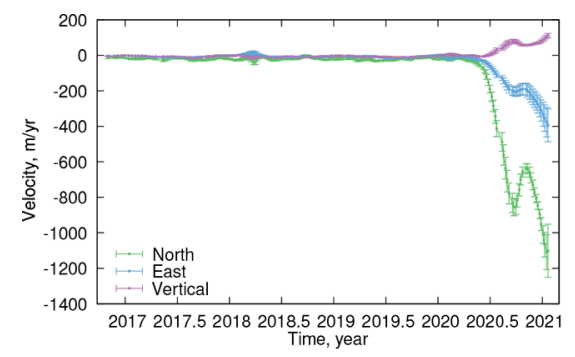

(a) P1

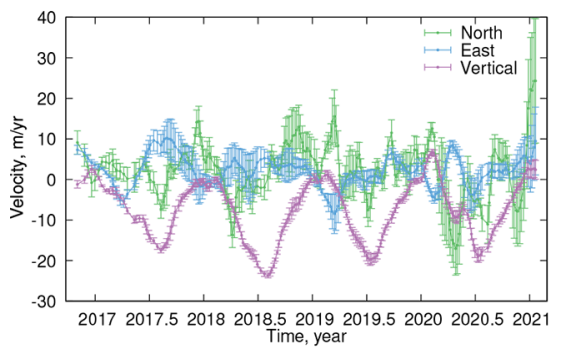

(d) P4

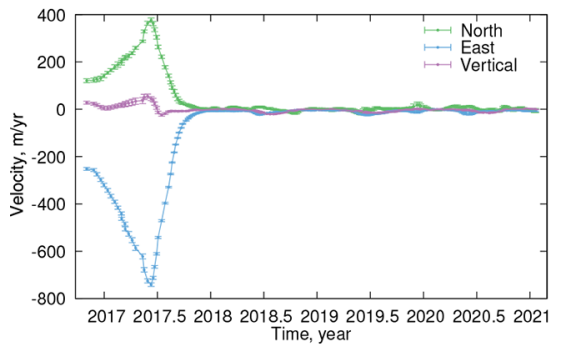

(g) P7

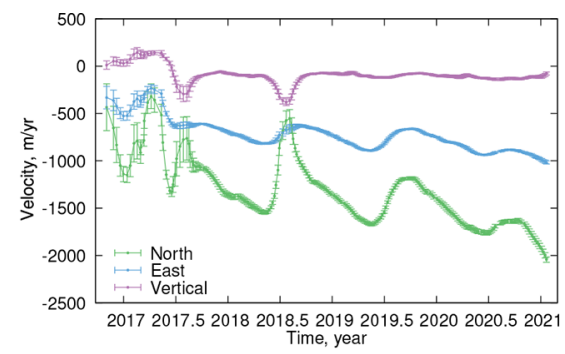

(b) P2

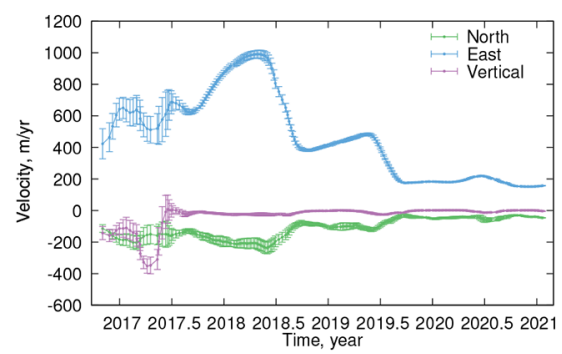

(e) P5

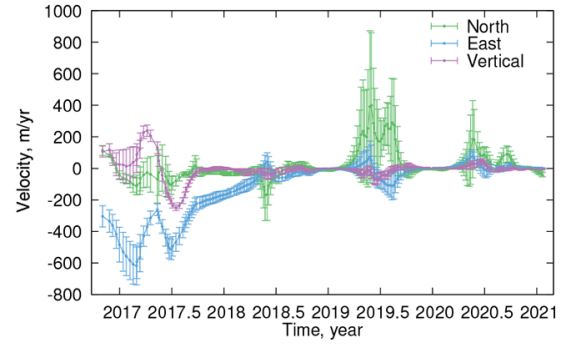

(h) P8

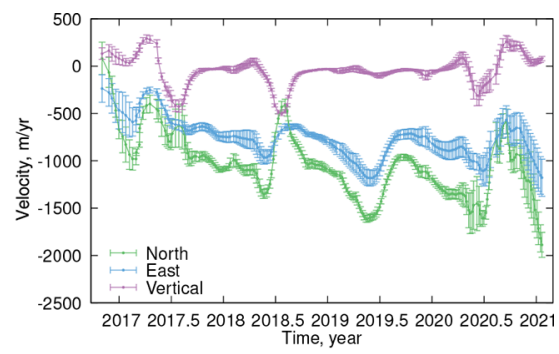

(c) P3

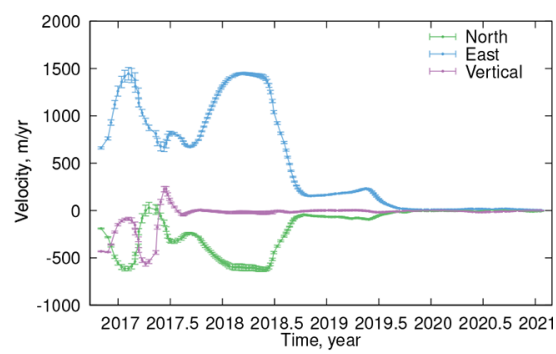

(f) P6

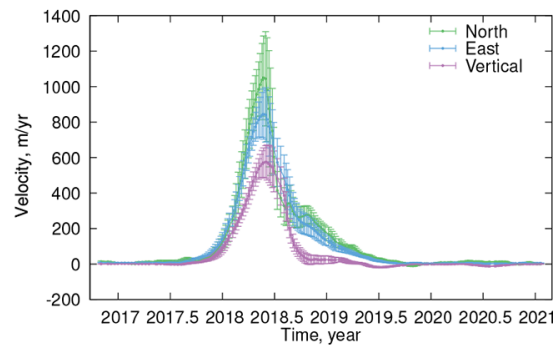

(i) $\mathrm{P} 9$

Figure 12. 3D flow velocity time series for regions P1-P9, the locations of which are shown in Figs. 6-10.

tively. At P7, northwest upward displacement is observed until July 2017 when a gradual reduction occurred. Region P9 is located on Kluane Glacier at an elevation of about $1700 \mathrm{~m}$. Here, southeast and upward displacement is observed during 2018 when a gradual reduction occurred. Error bars throughout Figs. 11 and 12 show measurement variability within the $5 \times 5$ pixel region rather than precision, though the two quantities are likely related.

\section{Discussion}

The technique presented in this study is a viable solution for computing 3D flow displacement time series from ascending and descending range and azimuth SAR measurements. Synthetic tests (Figs. 2 and 3) suggest that the precision of the inversion largely depends on the precision of input data and is not limited by the Sentinel-1 suboptimal acquisition geometry (i.e., nonorthogonal orbits). Range offsets can be substituted or complemented with DInSAR measurements since both measure the same quantity; similarly, azimuth offsets can be substituted or complemented by multiple-aperture interferometry (MAI) (Bechor and Zebker, 2006) measurements. For high-resolution SAR data, the precision of the SPO technique approaches that of DInSAR. In addition to glaciers, this technique can be used to study other geophysical processes (e.g., landslides, sea-river-lake ice drift) if their motion exceeds the sensitivity of SPO and/or MAI techniques.

The reported precision of the individual offset maps computed using the SPO technique is $1 / 10-1 / 30$ of the SAR pixel size (Strozzi et al., 2002). An average precision of our speckle offset product computed over a typical interval of $12 \mathrm{~d}$ (i.e., Sentinel-1 repeat period) is about $1 \mathrm{~m}$ (or $30 \mathrm{~m} \mathrm{yr}^{-1}$ ) in range and $4 \mathrm{~m}$ (or $120 \mathrm{~m} \mathrm{yr}^{-1}$ ) in azimuth. Our precision is lower than reported in Strozzi et al. (2002) because we intentionally interpret the motion outside glaciers (e.g., irregular snowdrift, landslides) as noise. However, for computing the mean linear velocity the length of the time series is more important than the precision of individual measurements. Standard deviations of the mean linear velocities averaged over the entire region are $0.7,0.3$, and $0.2 \mathrm{~m} \mathrm{yr}^{-1}$ (while the maximum values are 21,18 , and $7 \mathrm{~m} \mathrm{yr}^{-1}$, these higher values would be due to seasonal vari- 
ations and changes in surge activity) for northward, eastward, and vertical components, respectively. This is somewhat analogous to the precision of GNSS-derived deformation rates, which largely depend on the length of time series rather than the precision of individual GNSS measurements. The best approach for estimating the absolute measurement accuracy, of course, is comparing these remote sensing measurements with ground-based measurements (Gudmundsson and Bauder, 1999), which unfortunately are not available for this region and this period. SAR measures glacier motion at a certain depth rather than at the surface. Previous studies for this region suggest that the C-band SAR penetrates $\sim 4 \mathrm{~m}$ into the glacier's firn layer in dry conditions (Rignot et al., 2001). The standard deviation and coefficient of determination for each component of velocity and each pixel are provided in the Supplement.

One of the practical computational challenges of the SPO technique is the selection of pixels, the offsets of which are computed with high confidence. After multiple tests, we determined that the SNR function works very well for this purpose but only when the search window is large. However, such a large window applied to the medium-resolution SAR data limits the spatial resolution of the results. It is possible to use high-resolution SAR data and the $128 \times 28$ pixel search window to overcome this limitation and achieve a high spatial resolution of results; however, such SAR data are not yet readily available on a global scale. The utilization of highresolution SAR data also allows for the use of a spatial filter with a large window size in terms of pixels.

We compared the magnitude of mean linear horizontal flow velocities along the four profiles with the results presented in Gardner et al. (2019). There, surface velocities are derived from Landsat $4,5,7$, and 8 imagery over the period from 1985 to 2018 using the autoRIFT feature-tracking processing chain described in Gardner et al. (2018). We used the horizontal velocities computed during 2017, 2018, and the entire 2018-present period; these results are shown in the Supplement. The velocities computed over the 2017 and 2018 periods (Figs. S7-S14 in the Supplement) are in reasonable agreement. When we compare entire datasets (Figs. S15-S18 in the Supplement) they still show some agreement. Statistical parameters, such as correlation coefficients and room mean square errors (RMSEs), are provided in the figure captions. We observe that in areas experiencing nearly constant flow velocity, for example at Seward and Malaspina glaciers, both datasets show close results with a correlation of 0.93 and RMSE of $269 \mathrm{~m} \mathrm{yr}^{-1}$. At Klutlan, Walsh, and Kluane glaciers, SAR-derived velocities are affected by the surges, which are not reflected in Gardner et al. (2019), resulting in a lower correlation (0.43-0.80) and a larger RMSE (80-266 $\mathrm{m} \mathrm{yr}^{-1}$ ) in comparison to the average velocity at those glaciers. Furthermore, the Landsat record will be temporally biased towards cloud-free images and periods when sufficient sunlight is available to obtain optical imagery, thus eliminating a significant portion of late fall and early winter scenes. One final discrepancy can be attributed to the differences in processing parameters, such as correlation window and filter shape and strength. Significant filtering is required in our processing because, for time series analysis, every single range and azimuth offset map must be defined at every pixel, which can be only achieved by using a large correlation window followed by strong filtering. Preservation of spatial coverage in every single range and azimuth offset map forces us to select pixels with a moderate signalto-noise ratio (SNR), which would not have been selected if we wanted to compute only the mean velocity. Our software can potentially handle missing values in data by interpolating in the time domain (using first- and second-order regularizations), but here we have chosen not to introduce interpolation bias and instead lowered the SNR. Overall, in addition to providing the three components of flow velocity at a higher and more consistent temporal resolution, our study demonstrates that deviations from the mean flow velocity can be very significant. Although the time series in Fig. 11 resemble GNSSderived displacements, it is important to remember that these Eulerian measurements represent the cumulative displacement at any one pixel over time. Hence, to emphasize this difference, we use the flow displacement terminology. Note also that the vertical velocities do not represent rates of elevation change but evolving submergence and emergence velocities indicative of broader (and faster) changes in dynamic configuration than previously understood.

The overall direction of vertical flow is down along almost the entire length of the Seward and Malaspina glaciers (Fig. 7). The downward flow is expected in the upper reaches of accumulation zones because of firn compaction and in areas with steeply dipping surfaces due to sloping bed topography; however, downward flow, with the slope steeper than surface topography in the lower ablation zone, is of particular interest. In general, the accumulation of snow and ice in high elevations produces a net mass gain that replenishes ice lost through ablation processes along the lower glacier. In a steady state, these processes balance each other and lead to submergent flow in the accumulation zone and emergent flow in the ablation zone; thus, ice mass lost through melt in the ablation zone is replenished by ice that emerges from the depths of ice columns to the glacier surface to maintain a consistent surface elevation (Hooke, 2019). The predominately downward flow of ice observed throughout the Malaspina Glacier's massive lobe (Figs. 7b, c, e, and 12d) indicates that ablation rates have exceeded emergence velocities during our 4-year study period, implying that the glacier is still adjusting to climatic warming. Indeed, the Seward, Malaspina, and Agassiz glaciers are not in a steady state (Muskett et al., 2003; Larsen et al., 2015). Seasonal variability is observed along the Seward and Malaspina glaciers (Figs. 7d, e and 12b, c, d). The fastest horizontal motion occurs during late spring-early summer and the slowest in late summer-early fall, consistent with other glaciers in the region (Abe and Furuya, 2015; Vijay and Braun, 2017; Ender- 
lin et al., 2018). The fastest vertical motion is observed in the middle of summer. An animation provided with the Supplement clearly shows seasonality in flow rates over the entire complex. Seasonal variability at $\mathrm{P} 1$ is obstructed by a manyfold increase in velocity observed in the second half of 2020 that persists at the time of this study.

Velocities along Klutlan Glacier vary in more complex ways, with multiple zones of upward and downward flow observed (Fig. 8). This surge-type glacier (RGI Consortium, 2017) has a 30- to 60-year surge cycle (Meier and Post, 1969; Wright, 1980; Driscoll, 1980). Altena et al. (2019) used optical satellite data to show that its most recent surge initiated in 2014 and continued through 2017. The surge started mid-glacier and had two propagating fronts: a dominant surge front that propagated downglacier and a secondary subdued front that propagated upglacier. Our SAR-based record shows that surge activity terminated in mid-2018. The time series at P5 and P6 (Figs. 11e, f and 12e, f) show complex flow dynamics in both the horizontal and vertical components.

The Walsh Glacier is another surge-type glacier with recent surge activity. Using optical Landsat data, Fu and Zhou (2020) showed that the latest surge initiated before 2015 (Fig. 9). Our SAR-based observations show residual surge activity continued into 2017 and abruptly ended in mid-2017 (Fig. 9d). The time series at P8 (Figs. 11h and 12h) show that regular increases in flow velocity during summer, while at $\mathrm{P} 7$ these seasonal increases are less pronounced (Figs. 11g and 12g). The surge at P7 during 2017 is a dominant signal.

A surge of the Kluane Glacier has previously been detected using RADARSAT-2 SAR measurements (Main et al., 2019). It occurred during 2018 in a secondary valley of the glacier (Fig. 10). The entire surge cycle is captured by our time series (Figs. 11i and 12i). Such a complex flow pattern can only be derived from side-looking SAR measurements that capture horizontal and vertical components of motion.

These six in-depth-analyzed glaciers were selected from the regional results shown in Fig. 6. Other glaciers in this region may have also experienced surges or other interesting behaviors. The entire dataset, which includes instantaneous velocities and cumulative displacements for each pixel, and the processing software are provided with this paper.

\section{Conclusions}

We presented a flow displacement technique to observe variations in glacier surface flow in 3D using ascending and descending SAR scenes. The 3D flow displacement (and/or velocity) time series computed allowed us to map in unprecedented detail the state and the temporal evolution of six glaciers in southeastern Alaska during 20 October 201621 January 2021. On a broader scale, this technique can be used for reconstructing the historic response of worldwide glaciers to the warming climate using over 30 years of avail- able satellite SAR records. The horizontal components can be resolved to study flow variations over time and, if integrated along a profile that is perpendicular to flow, ice flux. The vertical component can be used to assess changes in vertical ice flux or changes in surface slope over time, which is useful for studying glacier surge dynamics or variations in driving stress as a glacier dynamically adjusts to a changing climate. The software is freely available to the research community.

Code and data availability. The range and azimuth offsets computed from Sentinel-1 data as well as all derived products and processing software used in this study can be downloaded from Mendeley Data at https://doi.org/10.17632/zf67rsgydv.1 (Samsonov et al., 2021b).

Video supplement. The animations of flow velocities for studied glaciers (files movie_malaspina.gif, movie_klutlan.gif, movie_walsh.gif, movie_kluane.gif) are provided. Comparisons between the magnitude of mean linear horizontal flow velocities along the four profiles with the results presented in Gardner et al. (2019) are also provided.

Supplement. The supplement related to this article is available online at: https://doi.org/10.5194/tc-15-4221-2021-supplement.

Author contributions. SeS was responsible for conceptualization, data curation, formal analysis, investigation, methodology, project administration, resources, software, visualization, and writing (original draft; review and editing). KT was responsible for investigation, formal analysis, methodology, and writing (review and editing). RC was responsible for investigation, formal analysis, methodology, and writing (review and editing).

Competing interests. The authors declare that they have no conflict of interest.

Disclaimer. Publisher's note: Copernicus Publications remains neutral with regard to jurisdictional claims in published maps and institutional affiliations.

Acknowledgements. We thank the European Space Agency for acquiring and the National Aeronautics and Space Administration (NASA) and ASF for distributing Sentinel-1 SAR data. Figures were plotted with GMT and Gnuplot software. The work of Sergey Samsonov was supported by the Canadian Space Agency through the Data Utilization and Application Plan (DUAP) program. The work of Kristy Tiampo was supported by CIRES, University of Colorado Boulder. 
Financial support. The work of Ryan Cassotto was supported by NASA (grant no. 80NSSC17K0017).

Review statement. This paper was edited by Joseph MacGregor and reviewed by Brent Minchew and two anonymous referees.

\section{References}

Abe, T. and Furuya, M.: Winter speed-up of quiescent surgetype glaciers in Yukon, Canada, The Cryosphere, 9, 1183-1190, https://doi.org/10.5194/tc-9-1183-2015, 2015.

Abrams, M., Crippen, R., and Fujisada, H.: ASTER Global Digital Elevation Model (GDEM) and ASTER Global Water Body Dataset (ASTWBD)., Remote Sens.-Basel, 12, 1156, https://doi.org/10.3390/rs12071156, 2020.

Altena, B., Scambos, T., Fahnestock, M., and Kääb, A.: Extracting recent short-term glacier velocity evolution over southern Alaska and the Yukon from a large collection of Landsat data, The Cryosphere, 13, 795-814, https://doi.org/10.5194/tc13-795-2019, 2019.

Arendt, A.: Assessing the Status of Alaska's Glaciers, Science, 332, 1044-1045, https://doi.org/10.1126/science.1204400, 2011.

Arendt, A., Walsh, J., and Harrison, W.: Changes of glaciers and climate in northwestern North America during the late twentieth century, J. Climate, 22, 4117-4134, https://doi.org/10.1175/2009JCLI2784.1, 2009.

Bartholomew, I., Nienow, P., Mair, D., Hubbard, A., King, M., and Sole, A.: Seasonal evolution of subglacial drainage and acceleration in a Greenland outlet glacier, Nat. Geosci., 3, 408-411, https://doi.org/10.1038/ngeo863, 2010.

Bechor, N. and Zebker, H.: Measuring two-dimensional movements using a single InSAR pair, Geophys. Res. Lett., 33, L16311, https://doi.org/10.1029/2006GL026883, 2006.

Berthier, E., Vadon, H., Baratoux, D., Arnaud, Y., Vincent, C., Feigl, K., Remy, F., and Legresy, B.: Surface motion of mountain glaciers derived from satellite optical imagery, Remote Sens. Environ., 95, 14-28, https://doi.org/10.1016/j.rse.2004.11.005, 2005.

Bisset, R., Dehecq, A., Goldberg, D., Huss, M., Bingham, R., and Gourmelen, N.: Reversed Surface-Mass-Balance Gradients on Himalayan Debris-Covered Glaciers Inferred from Remote Sensing, Remote Sens.-Basel, 12, 1563, https://doi.org/10.3390/rs12101563, 2020.

Burgess, E., Forster, R., and Larsen, C.: Flow velocities of Alaskan glaciers, Nat. Commun., 4, 2146, https://doi.org/10.1038/ncomms3146, 2013.

Dehecq, A., Gourmelen, N., and Trouve, E.: Deriving large-scale glacier velocities from a complete satellite archive: Application to the Pamir-Karakoram-Himalaya, Remote Sens. Environ., 162, 55-66, https://doi.org/10.1016/j.rse.2015.01.031, 2015.

Driscoll, F. J.: Formation of the neoglacial surge moraines of the Klutlan glacier, Yukon Territory, Canada, Quaternary Res., 1930, https://doi.org/10.1016/0033-5894(80)90004-6, 1980.

Enderlin, E. M., O’Neel, S., Bartholomaus, T. C., and Joughin, I.: Evolving Environmental and Geometric Controls on Columbia Glacier's Continued Retreat, J. Geophys. Res.-Earth, 123, 15281545, https://doi.org/10.1029/2017JF004541, 2018.
Fahnestock, M., Scambos, T., Moon, T., Gardner, A., Haran, T., and Klinger, M.: Rapid large-area mapping of ice flow using Landsat 8, Remote Sens. Environ., Remote Sens. Environ., 185, 84-94, https://doi.org/10.1016/j.rse.2015.11.023, 2015.

Fahnestock, M., Scambos, T., Moon, T., Gardner, A., Haran, T., and Klinger, M.: Rapid large-area mapping of ice flow using Landsat 8, Remote Sens. Environ., 185, 84-94, https://doi.org/10.1016/j.rse.2015.11.023, 2016.

Fialko, Y., Simons, M., and Agnew, D.: The complete (3D) surface displacement field in the epicentral area of the 1999 MW7.1 Hector Mine Earthquake, California, from space geodetic observations, Geophys. Res. Lett., 28, 3063-3066, https://doi.org/10.1029/2001GL013174, 2001.

Ford, A. L., Forster, R. R., and Bruhn, R. L.: Ice surface velocity patterns on Seward Glacier, Alaska/Yukon, and their implications for regional tectonics in the Saint Elias Mountains, Ann. Glaciol., 36, 21-28, https://doi.org/10.3189/172756403781816086, 2003.

$\mathrm{Fu}, \mathrm{X}$. and Zhou, J.: Recent surge behavior of Walsh glacier revealed by remote sensing data, Sensors, 20, 716, https://doi.org/10.3390/s20030716, 2020.

Gardner, A. S., Moholdt, G., Scambos, T., Fahnstock, M., Ligtenberg, S., van den Broeke, M., and Nilsson, J.: Increased West Antarctic and unchanged East Antarctic ice discharge over the last 7 years, The Cryosphere, 12, 521-547, https://doi.org/10.5194/tc-12-521-2018, 2018.

Gardner, A., Fahnestock, M., and Scambos, T.: ITS_LIVE Regional Glacier and Ice Sheet Surface Velocities, Data archived at National Snow and Ice Data Center, https://doi.org/10.5067/6II6VW8LLWJ7, 2019.

Goldstein, R. M., Engelhardt, H., Kamb, B., and Frolich, R. M.: Satellite Radar Interferometry for Monitoring Ice Sheet Motion: Application to an Antarctic Ice Stream, Science, 262, 15251530, https://doi.org/10.1126/science.262.5139.1525, 1993.

Gourmelen, N., Amelung, F., Casu, F., Manzo, M., and Lanari, R.: Mining-related ground deformation in Crescent Valley, Nevada: Implications for sparse GPS networks, Geophys. Res. Lett., 34, L09309, https://doi.org/10.1029/2007GL029427, 2007.

Gourmelen, N., Amelung, F., and Lanari, R.: Interferometric synthetic aperture radar-GPS integration: Interseismic strain accumulation across the Hunter Mountain fault in the eastern California shear zone, J. Geophys. Res.-Sol. Ea., 115, B09408, https://doi.org/10.1029/2009JB007064, 2010.

Gourmelen, N., Kim, S., Shepherd, A., Park, J., Sundal, A., Björnsson, H., and Pálsson, F.: Ice velocity determined using conventional and multiple-aperture InSAR, Earth Planet. Sc. Lett., 307, 156-160, https://doi.org/10.1016/j.eps1.2011.04.026, 2011.

Gray, L.: Using multiple RADARSAT InSAR pairs to estimate a full three-dimensional solution for glacial ice movement, Geophys. Res. Lett., 38, L05502, https://doi.org/10.1029/2010GL046484, 2011.

Gray, L., Joughin, I., Tulaczyk, S., Spikes, V., Bindschadler, R., and Jezek, K.: Evidence for subglacial water transport in the West Antarctic Ice Sheet through three-dimensional satellite radar interferometry, Geophys. Res. Lett., 32, L03501, https://doi.org/10.1029/2004GL021387, 2005.

Gudmundsson, G. and Bauder, A.: Towards an Indirect Determination of the Mass-Balance Distribution of Glaciers Using the Kinematic Boundary Condition, Geogr. Ann. A, 81, 575-583, 1999. 
Guo, L., Li, J., Li, Z.-w., Wu, L.-x., Li, X., Hu, J., Li, H.-1., Li, H.-y., Miao, Z.-1., and Li, Z.-q.: The Surge of the Hispar Glacier, Central Karakoram: SAR 3-D Flow Velocity Time Series and Thickness Changes, J. Geophys. Res.-Sol. Ea., 125, e2019JB018945, https://doi.org/10.1029/2019JB018945, 2020.

Hansen, P. and O'Leary, D.: The use of the L-curve in the regularization of discrete ill-posed problems, SIAM J. Sci. Comput., 14, 1487-1503, 1993.

Herman, F., Anderson, B., and Leprince, S.: Mountain glacier velocity variation during a retreat/advance cycle quantified using sub-pixel analysis of ASTER images, J. Glaciol., 57, 197-207, https://doi.org/10.3189/002214311796405942, 2011.

Hooke, R. L.: Principles of Glacier Mechanics, Cambridge University Press, 3rd edn., https://doi.org/10.1017/9781108698207, 2019.

Hu, J., Li, Z., Ding, X., Zhu, J., Zhang, L., and Sun, Q.: Resolving three-dimensional surface displacements from InSAR measurements: A review, Earth-Sci. Rev., 133, 1-17, https://doi.org/10.1016/j.earscirev.2014.02.005, 2014.

Immerzeel, W., Kraaijenbrink, P., Shea, J., Shrestha, A., Pellicciotti, F., Bierkens, M., and de Jong, S.: Highresolution monitoring of Himalayan glacier dynamics using unmanned aerial vehicles, Remote Sens. Environ., 150, 93-103, https://doi.org/10.1016/j.rse.2014.04.025, 2014.

Joughin, I.: Ice-sheet velocity mapping: A combined interferometric and speckle-tracking approach, Ann. Glaciol., 34, 195-201, https://doi.org/10.3189/172756402781817978, 2002.

Joughin, I., Winebrenner, D., and Fahnestock, M.: Observations of ice-sheet motion in Greenland using satellite radar interferometry, Geophys. Res. Lett., 22, 571-574, https://doi.org/10.1029/95GL00264, 1995.

Joughin, I., Kwok, R., and Fahnestock, M.: Interferometric estimation of three-dimensional ice-flow using ascending and descending passes, IEEE T. Geosci. Remote, 36, 25-37, https://doi.org/10.1109/36.655315, 1998.

Kumar, V., Venkataramana, G., and Høgda, K.: Glacier surface velocity estimation using SAR interferometry technique applying ascending and descending passes in Himalayas, Int. J. Appl. Earth Obs., 13, 545-551, https://doi.org/10.1016/j.jag.2011.02.004, 2011.

Larsen, C., Burgess, E., Arendt, A. A., O’Neel, S., Johnson, A. J., and Kienholz, C.: Surface melt dominates Alaska glacier mass balance, Geophys. Res. Lett., 42, 5902-5908, https://doi.org/10.1002/2015GL064349, 2015.

Main, B., Copland, L., Samsonov, S., Dow, C., Flowers, G., Young, E., and Kochtitzky, W.: Surge of Little Kluane Glacier in the St. Elias Mountains, Yukon, Canada, from 2017-2018, in: American Geophysical Union, Fall Meeting, 9-13 December 2019, San Francisco. abstract C31B-1517, 2019.

Massonnet, D. and Feigl, K.: Discrimination of geophysical phenomena in satellite radar interferograms, Geophys. Res. Lett., 22, 1537-1540, 1995.

Maussion, F., Butenko, A., Champollion, N., Dusch, M., Eis, J., Fourteau, K., Gregor, P., Jarosch, A. H., Landmann, J., Oesterle, F., Recinos, B., Rothenpieler, T., Vlug, A., Wild, C. T., and Marzeion, B.: The Open Global Glacier Model (OGGM) v1.1, Geosci. Model Dev., 12, 909-931, https://doi.org/10.5194/gmd12-909-2019, 2019.
Meier, M. and Post, A.: What are glacier surges?, Can. J. Earth Sci., 6, 807-817, https://doi.org/10.1139/e69-081, 1969.

Milillo, P., Minchew, B., Simons, M., Agram, P., and Riel, B.: Geodetic imaging of time-dependent three-component surface deformation: Application to tidal-timescale ice flow of Rutford Ice Stream, West Antarctica, IEEE T. Geosci. Remote, 55, 55155524, https://doi.org/10.1109/TGRS.2017.2709783, 2017.

Minchew, B. M., Simons, M., Riel, B., and Milillo, P.: Tidally induced variations in vertical and horizontal motion on Rutford Ice Stream, West Antarctica, inferred from remotely sensed observations, J. Geophys. Res.-Earth, 122, 167-190, https://doi.org/10.1002/2016JF003971, 2017.

Mohr, J., Reeh, N., and Madsen, S.: Three-dimensional glacial flow and surface elevation measured with radar interferometry, Nature, 391, 273-276, https://doi.org/10.1038/34635, 1998.

Morlighem, M., Rignot, E., Seroussi, H., Larour, E., Ben Dhia, H., and Aubry, D.: A mass conservation approach for mapping glacier ice thickness, Geophys. Res. Lett., 38, L19503, https://doi.org/10.1029/2011GL048659, 2011.

Muskett, R. R., Lingle, C. S., Tangborn, W. V., and Rabus, B. T.: Multi-decadal elevation changes on Bagley Ice Valley and Malaspina Glacier, Alaska, Geophys. Res. Lett., 30, 1857, https://doi.org/10.1029/2003GL017707, 2003.

Palmer, S. J., Shepherd, A., Sundal, A., Rinne, E., and Nienow, P.: InSAR observations of ice elevation and velocity fluctuations at the Flade Isblink ice cap, eastern North Greenland, J. Geophys. Res.-Earth, 115, F04037, https://doi.org/10.1029/2010JF001686, 2010.

RGI Consortium: Randolph Glacier Inventory - A Dataset of Global Glacier Outlines: Version 6.0: Technical Report, Global Land Ice Measurements from Space, Tech. rep., Colorado, USA, Digital Media, https://doi.org/10.7265/N5-RGI-60, 2017.

Riel, B., Simons, M., Agram, P., and Zhan, Z.: Detecting transient signals in geodetic time series using sparse estimation techniques, J. Geophys. Res.-Solid, 119, 5140-5160, https://doi.org/10.1002/2014JB011077, 2014.

Riel, B., Simons, M., Ponti, D., and Agram, P.and Jolivet, R.: Quantifying ground deformation in the Los Angeles and Santa Ana Coastal Basins due to groundwater withdrawal, Water Resour. Res., 54, 3557-3582, https://doi.org/10.1029/2017WR021978, 2018.

Riel, B., Minchew, B., and Joughin, I.: Observing traveling waves in glaciers with remote sensing: new flexible time series methods and application to Sermeq Kujalleq (Jakobshavn Isbræ), Greenland, The Cryosphere, 15, 407-429, https://doi.org/10.5194/tc15-407-2021, 2021.

Rignot, E.: Fast Recession of a West Antarctic Glacier, Science, 281, 549-551, https://doi.org/10.1126/science.281.5376.549, 1998.

Rignot, E.: Mass balance of East Antarctic glaciers and ice shelves from satellite data, Ann. Glaciol., 34, 217-227, https://doi.org/10.3189/172756402781817419, 2002.

Rignot, E., Echelmeyer, K., and Krabill, W.: Penetration depth of interferometric synthetic-aperture radar signals in snow and ice, Geophys. Res. Lett., 28, 3501-3504, https://doi.org/10.1029/2000GL012484, 2001.

Rosen, P., Hensley, P., Joughin, I., Li, F., Madsen, S., Rodriguez, E., and Goldstein, R.: Synthetic aperture radar interferometry, P. IEEE, 88, 333-382, 2000. 
Samsonov, S.: Three-dimensional deformation time series of glacier motion from multiple-aperture DInSAR observation, J. Geodesy, 93, 2651-2660, https://doi.org/10.1007/s00190-01901325-y, 2019.

Samsonov, S. and d'Oreye, N.: Multidimensional time series analysis of ground deformation from multiple InSAR data sets applied to Virunga Volcanic Province, Geophys. J. Int., 191, 1095-1108, https://doi.org/10.1111/j.1365-246X.2012.05669.x, 2012.

Samsonov, S. and d'Oreye, N.: Multidimensional Small Baseline Subset (MSBAS) for Two-Dimensional Deformation Analysis: Case Study Mexico City, Can. J. Remote Sens., 43, 318-329, https://doi.org/10.1080/07038992.2017.1344926, 2017.

Samsonov, S. and Tiampo, K.: Analytical optimization of DInSAR and GPS dataset for derivation of three-dimensional surface motion, IEEE Geosci. Remote S., 3, 107-111, 2006.

Samsonov, S., Tiampo, K., Rundle, J., and Li, Z.: Application of DInSAR-GPS optimization for derivation of fine scale surface motion maps of southern California, IEEE T. Geosci. Remote, 45, 512-521, 2007.

Samsonov, S., Dille, A., Dewitte, O., Kervyn, F., and d'Oreye, N.: Satellite interferometry for mapping surface deformation time series in one, two and three dimensions: A new method illustrated on a slow-moving landslide, Eng. Geol., 266, 105471, https://doi.org/10.1016/j.enggeo.2019.105471, 2020.

Samsonov, S., Tiampo, K., and Cassotto, R.: SAR-derived flow velocity and its link to glacier surface elevation change and mass balance, Remote Sens. Environ., 258, 112343, https://doi.org/10.1016/j.rse.2021.112343, 2021a.

Samsonov, S., Tiampo, K., and Cassotto, R.: "Data for: Measuring the state and temporal evolution of glaciers in Alaska and Yukon using SAR-derived 3D time series of glacier surface flow", Mendeley Data, V1, https://doi.org/10.17632/zf67rsgydv.1, $2021 b$.

Sauber, J., Molnia, B., Carabajal, C., Luthcke, S., and Muskett, R.: Ice elevations and surface change on the Malaspina Glacier, Alaska, Geophys. Res. Lett., 32, L23S01, https://doi.org/10.1029/2005GL023943, 2005.

Sharp, R. P.: Accumulation and ablation on the SewardMalaspina glacier system, Canada-Alaska, GSA Bulletin, $\quad 62, \quad 725-744, \quad$ https://doi.org/10.1130/00167606(1951)62[725:AAAOTS]2.0.CO;2, 1951.

Sharp, R. P.: Malaspina Glacier, Alaska, Geol. Soc. Am. Bull., 69, 617-646, https://doi.org/10.1130/00167606(1958)69[617:MGA]2.0.CO;2, 1958.

Shen, Z.-K. and Liu, Z.: Integration of GPS and InSAR data for resolving 3-dimensional crustal deformation, Earth and Space Science, 7, e2019EA001036, https://doi.org/10.1029/2019EA001036, 2020.
Shepherd, A., Wingham, D. J., Mansley, J. A. D., and Corr, H. F. J.: Inland Thinning of Pine Island Glacier, West Antarctica, Science, 291, 862-864, https://doi.org/10.1126/science.291.5505.862, 2001.

Shepherd, A., Ivins, E., and Rignot, E. e. a.: Mass balance of the Greenland Ice Sheet from 1992 to 2018., Nature, 579, 233-239, https://doi.org/10.1038/s41586-019-1855-2, 2020.

Strozzi, T., Luckman, A., Murray, T., and Wegmuller, U.and Werner, C. L.: Glacier motion estimation using SAR offset-tracking procedures, IEEE T. Geosci. Remote, 40, 2384-2391, https://doi.org/10.1109/TGRS.2002.805079, 2002.

van de Wal, R. S. W., Boot, W., van den Broeke, M. R., Smeets, C. J. P. P., Reijmer, C. H., Donker, J. J. A., and Oerlemans, J.: Large and Rapid Melt-Induced Velocity Changes in the Ablation Zone of the Greenland Ice Sheet, Science, 321, 111113, https://doi.org/10.1126/science.1158540, 2008.

Vijay, S. and Braun, M.: Seasonal and interannual variability of Columbia Glacier, Alaska (2011-2016): ice velocity, mass flux, surface elevation and front position, Remote Sens.-Basel, 9, 635, https://doi.org/10.3390/rs9060635, 2017.

Waechter, A., Copland, L., and Herdes, E.: Modern glacier velocities across the Icefield Ranges, St Elias Mountains, and variability at selected glaciers from 1959 to 2012, J. Glaciol., 61, 624-634, https://doi.org/10.3189/2015JoG14J147, 2015.

Wang, Q., Fan, J., Zhou, W., Tong, L., Guo, Z., Liu, G., Yuan, W., Sousa, J. J., and Perski, Z.: 3D Surface velocity retrieval of mountain glacier using an offset tracking technique applied to ascending and descending SAR constellation data: a case study of the Yiga Glacier, Int. J. Digit. Earth, 12, 614-624, https://doi.org/10.1080/17538947.2018.1470690, 2019.

Wegmuller, U. and Werner, C.: GAMMA SAR processor and interferometry software, in: The 3rd ERS symposium on space at the service of our environment, Florence, Italy, available at: https://earth.esa.int/workshops/ers97/papers/wegmuller2/, 1997.

Werder, M. A., Huss, M., Paul, F., Dehecq, A., and Farinotti, D.: A Bayesian ice thickness estimation model for large-scale applications, J. Glaciol., 66, 137-152, https://doi.org/10.1017/jog.2019.93, 2019.

Wright, H.: Surge Moraines of the Klutlan Glacier, Yukon Territory, Canada: Origin, Wastage, Vegetation Succession, Lake Development, and Application to the Late-Glacial of Minnesota, Quaternary Res., 14, 2-18, https://doi.org/10.1016/00335894(80)90003-4, 1980.

Wright, T., Parsons, B., and Lu, Z.: Toward mapping surface deformation in three dimensions using InSAR, Geophys. Res. Lett., 31, L01607, https://doi.org/10.1029/2003GL018827, 2004. 